\title{
Bioluminescence imaging of stroke-induced endogenous neural stem cell response
}

\author{
Caroline Vandeputte ${ }^{\text {a,b,c, }, 1}$, Veerle Reumers ${ }^{\mathrm{a}, 1}$, Sarah-Ann Aelvoet ${ }^{\mathrm{a}, 1}$, Irina Thiry ${ }^{\mathrm{d}}$, Sylvie De Swaef ${ }^{\mathrm{a}}$, \\ Chris Van den Haute ${ }^{\mathrm{a} e}$, Jesus Pascual-Brazo ${ }^{\mathrm{a}}$, Tracy D. Farr ${ }^{\mathrm{f}}$, Greetje Vande Velde ${ }^{\mathrm{b}, \mathrm{g}}$, Mathias Hoehn ${ }^{\mathrm{f}}$, \\ Uwe Himmelreich $^{\text {b,g }}$, Koen Van Laere ${ }^{\text {b,c }}$, Zeger Debyser ${ }^{\text {b,d }}$, Rik Gijsbers ${ }^{\text {d,e,* }}$, Veerle Baekelandt ${ }^{\text {a,b, } * *}$ \\ ${ }^{a}$ KU Leuven, Laboratory for Neurobiology and Gene Therapy, Department of Neurosciences, 3000 Leuven, Flanders, Belgium \\ ${ }^{\mathrm{b}}$ KU Leuven, Molecular Small Animal Imaging Center, MOSAIC, KU Leuven, 3000 Leuven, Flanders, Belgium \\ ' Division of Nuclear Medicine, University Hospital and KU Leuven, 3000 Leuven, Flanders, Belgium \\ ${ }^{d}$ KU Leuven, Laboratory for Molecular Virology and Gene Therapy, Department of Pharmaceutical and Pharmacological Sciences, 3000 Leuven, Flanders, Belgium \\ ${ }^{\text {e }}$ KU Leuven, Leuven Viral Vector Core, 3000 Leuven, Flanders, Belgium \\ ${ }^{\mathrm{f}}$ In-vivo-NMR Laboratory, Max Planck Institute for Neurological Research, 50931 Cologne, Germany \\ ${ }^{g}$ KU Leuven, Biomedical MRI, Department of Imaging and Pathology, 3000 Leuven, Flanders, Belgium
}

\section{A R T I C L E I N F O}

\section{Article history:}

Received 24 October 2013

Revised 15 March 2014

Accepted 17 May 2014

Available online 27 May 2014

\section{Keywords:}

Bioluminescence imaging

Cre-Flex lentiviral vector

Endogenous neural stem cells

Nestin-Cre mice

Stroke

\begin{abstract}
A B S T R A C T
Brain injury following stroke affects neurogenesis in the adult mammalian brain. However, a complete understanding of the origin and fate of the endogenous neural stem cells (eNSCs) in vivo is missing. Tools and technology that allow non-invasive imaging and tracking of eNSCs in living animals will help to overcome this hurdle. In this study, we aimed to monitor eNSCs in a photothrombotic (PT) stroke model using in vivo bioluminescence imaging (BLI). In a first strategy, inducible transgenic mice expressing firefly luciferase (Fluc) in the eNSCs were generated. In animals that received stroke, an increased BLI signal originating from the infarct region was observed. However, due to histological limitations, the identity and exact origin of cells contributing to the increased BLI signal could not be revealed. To overcome this limitation, we developed an alternative strategy employing stereotactic injection of conditional lentiviral vectors (Cre-Flex LVs) encoding Fluc and eGFP in the subventricular zone (SVZ) of Nestin-Cre transgenic mice, thereby specifically labeling the eNSCs. Upon induction of stroke, increased eNSC proliferation resulted in a significant increase in BLI signal between 2 days and 2 weeks after stroke, decreasing after 3 months. Additionally, the BLI signal relocalized from the SVZ towards the infarct region during the 2 weeks following stroke. Histological analysis at 90 days post stroke showed that in the periinfarct area, $36 \%$ of labeled eNSC progeny differentiated into astrocytes, while $21 \%$ differentiated into mature neurons. In conclusion, we developed and validated a novel imaging technique that unequivocally demonstrates that nestin $^{+}$eNSCs originating from the SVZ respond to stroke injury by increased proliferation, migration towards the infarct region and differentiation into both astrocytes and neurons. In addition, this new approach allows non-invasive and specific monitoring of eNSCs over time, opening perspectives for preclinical evaluation of candidate stroke therapeutics.
\end{abstract}

(c) 2014 Elsevier Inc. All rights reserved.

Abbreviations: BLI, bioluminescence imaging; BrdU, 5-bromo-2'-deoxyuridine; CC, corpus callosum; Cre-Flex, Cre-mediated flip-excision; DCX, doublecortin; eNSCs, endogenous neu-

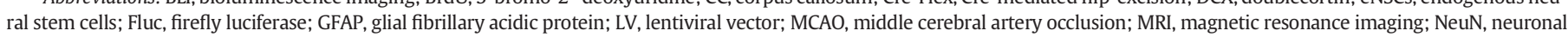
nuclei; OB, olfactory bulb; PET, positron emission tomography; PT, photothrombotic; RMS, rostral migratory stream; SGZ, subgranular zone; SVZ, subventricular zone.

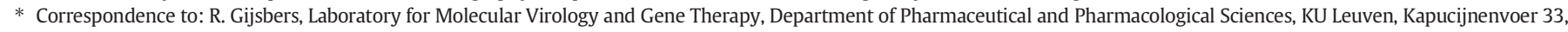
VCTB +5 bus 7001, B-3000 Leuven, Flanders, Belgium. Fax: + 3216336336.

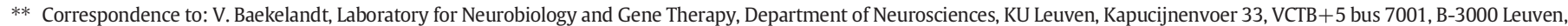
Flanders, Belgium. Fax: + 3216336336 .

E-mail addresses: rik.gijsbers@med.kuleuven.be (R. Gijsbers), veerle.baekelandt@med.kuleuven.be (V. Baekelandt).

URL's: http://www.kuleuven.be/molmedsame (R. Gijsbers), http://www.kuleuven.be/molmedsame (V. Baekelandt).

Available online on ScienceDirect (www.sciencedirect.com).

1 These authors contributed equally. 


\section{Introduction}

The presence of endogenous neural stem cells (eNSCs) in the adult mammalian brain, including human brain, is now widely accepted (Altman, 1962, 1963; Curtis et al., 2005; Eriksson et al., 1998). Two brain regions, i.e. the SVZ of the lateral ventricles and the subgranular zone (SGZ) of the hippocampal dentate gyrus, are recognized as primary regions of adult neurogenesis (Ming and Song, 2005). Under physiological conditions, eNSCs in the SVZ divide and their progeny migrates tangentially via the rostral migratory stream (RMS) to the olfactory bulb (OB). Upon arrival in the $\mathrm{OB}$, neuroblasts differentiate into local interneurons and integrate into the glomerular and granular layers (Alvarez-Buylla and Garcia-Verdugo, 2002). Pathological conditions, including brain injury and stroke, affect adult neurogenesis (Curtis et al., 2005; Gray and Sundstrom, 1998; Liu et al., 1998). Stroke, a common cause of morbidity and mortality worldwide, deprives the brain of oxygen and glucose (Flynn et al., 2008). Following stroke, neurogenesis augments the number of immature neurons in the SVZ (Jin et al., 2001; Zhang et al., 2008). Neuroblasts (positive for the marker doublecortin, DCX) migrate towards sites of ischemic damage and upon arrival, phenotypic markers of mature neurons can be detected (Arvidsson et al., 2002; Parent et al., 2002). On the other hand, retroviral labeling of the SVZ showed that cells migrated to the lesion and differentiated into glia (Goings et al., 2004), demonstrating that following injury, the SVZ can generate both neural cell types. Some studies showed that SVZ-derived progenitors can differentiate into medium spiny neurons in the striatum after stroke (Collin et al., 2005; Parent et al., 2002), whereas others claimed that the newborn cells are fate restricted to interneurons or glia (Deierborg et al., 2009; Liu et al., 2009). Whether SVZ neural progenitors can alter their fate, integrate in the injured circuits and survive for long time periods is still a matter of debate (Kernie and Parent, 2010). Up till now, specific labeling of eNSCs in the SVZ and the follow-up of the migration of their progeny to the ischemic area over time has not yet been shown.

Apart from the primary neurogenic niches, other brain regions, e.g. the cortex, contain cells that become multipotent and self-renew after injury (Komitova et al., 2006). Although mature astrocytes do not divide in healthy conditions, they can dedifferentiate and proliferate after stab wound injury and stroke (Buffo et al., 2008; Sirko et al., 2013). While these proliferating astrocytes remained within their lineage in vivo, they formed multipotent neurospheres in vitro (Buffo et al., 2008; Shimada et al., 2010). Therefore, these reactive astrocytes may represent an alternative source of multipotent cells that may be beneficial in stroke.

A major hurdle when studying endogenous neurogenesis is the lack of methods to monitor these processes in vivo, in individual animals over time. We and others attempted to label eNSCs by injection of iron oxide-based particles in the lateral ventricle or SVZ (Nieman et al., 2010; Shapiro et al., 2006; Sumner et al., 2009; Vreys et al., 2010), or by lentiviral vectors (LVs) encoding a reporter gene into the SVZ (Vande Velde et al., 2012) to monitor stem cell migration along the RMS with magnetic resonance imaging (MRI). Although MRI provides high resolution, it suffers from low in vivo sensitivity and gives no information on cell viability and non-specific signal detection cannot be excluded. Rueger et al. described in vivo imaging of eNSCs after focal cerebral ischemia via positron emission tomography (PET) imaging (Rueger et al., 2010), however, the cells responsible for the PET signal could not be identified. Alternatively, transgenic mice expressing Fluc driven by a DCX promoter allowed monitoring of adult neurogenesis using in vivo BLI (Couillard-Despres et al., 2008). However, the robust BLI signal emitted from the SVZ, leading to scattering and projection of these photons to the OB, impedes direct visualization of eNSC migration from the SVZ towards the OB. Moreover, when the $\mathrm{DCX}^{+}$ neuroblasts differentiate into mature neurons, they lose the Fluc expression. In a first part of the present study, we generated inducible transgenic mice that express Fluc in the nestin ${ }^{+}$eNSCs, to monitor a stroke-induced eNSC response with BLI.
An alternative strategy to efficiently and stably introduce Fluc in the eNSCs is by stereotactic injection of LVs into the SVZ, which allowed us and others to monitor the migration of eNSCs and their progeny towards the OB with BLI (Guglielmetti et al., 2013; Reumers et al., 2008). However, since LVs transduce both dividing and post-mitotic cells, not only eNSCs but also neighboring astrocytes and mature neurons are labeled after injection of constitutive LVs in the SVZ (Geraerts et al., 2006). As a result, in line with the data described in transgenic mice, a high BLI signal emerges from the site of injection that interferes with the measurement of the migrating cells (Reumers et al., 2008). To overcome the latter, we developed new conditional Cre-Flex LVs in a second part of this study. These Cre-Flex LVs incorporate Cre-lox technology, allowing that Fluc and eGFP are restrictively expressed in eNSCs after injection in the SVZ of transgenic Nestin-Cre mice. While numerous research groups have previously described stroke-induced eNSC behavior (Arvidsson et al., 2002; Parent et al., 2002), we here report for the first time successful in vivo imaging and characterization of long-term eNSC responses after stroke.

\section{Materials \& methods}

\section{Animals}

Animal studies were performed in accordance with the current ethical regulations of the KU Leuven. Nestin-CreER ${ }^{\mathrm{T} 2}$ mice (a kind gift from Dr. Amelia J. Eisch (University of Texas Southwestern Medical Center, Dallas, TX) (Lagace et al., 2007)) and B6.Cg-Tg(Nes-cre) $1 \mathrm{Kln} / \mathrm{J}$ (Jax labs stock nr 003771, (Tronche et al., 1999)) were crossbred with C57BL/6-Tyr ${ }^{\mathrm{c}-2 \mathrm{~J}} / \mathrm{J}$ (Jax labs, stock nr 000058), creating white furred albino mice in a $\mathrm{C} 57 \mathrm{BL} / 6$ genetic background. White furred inducible Nestin-CreER ${ }^{\mathrm{T} 2}$ mice were crossbred with ROSA26-LoxPstop-LoxP(L-S-L)-luciferase transgenic mice (Safran et al., 2003) (Jax labs, stock nr 005125), indicated as Nestin-CreER ${ }^{\mathrm{T} 2} /$ Fluc mice. To induce Fluc expression, mice received tamoxifen intraperitoneally (ip) or orally at $180 \mathrm{mg} / \mathrm{kg}$ dissolved in $10 \% \mathrm{EtOH} / 90 \%$ sunflower oil for 5 consecutive days. BrdU was administered as previously published (Geraerts et al, 2006). For the stroke follow-up, Fluc expression was induced in 11 Nestin-CreER ${ }^{\mathrm{T} 2} /$ Fluc mice by oral tamoxifen treatment. Four days later, the animals were divided into 2 groups: 8 mice received a PT stroke and 2 mice received a sham treatment; one mouse died during tamoxifen induction. Three Cre-negative littermates that received a stroke were added as controls.

White furred B6.Cg-Tg(Nes-cre) $1 \mathrm{~K} \ln / \mathrm{J}$ mice, here referred to as Nestin-Cre mice, were stereotactically injected with Cre-Flex LV in the SVZ at the age of 8 weeks. One week after stereotactic injection, Nestin-Cre mice received a PT stroke $(\mathrm{n}=33)$ or sham treatment $(\mathrm{n}=10)$. A Cre-negative littermate that received a stroke was added as control.

Mice were genotyped by PCR using genomic DNA and primers previously described (Lagace et al., 2007).

\section{Lentiviral vector construction and production}

We designed a new conditional LV system based on the Cre/loxP mechanism, here referred to as Cre-Flex (Cre-mediated flip-excision). The Cre-Flex LVs carry a reporter cassette encoding eGFP and Fluc flanked by a pair of mutually exclusive lox sites. The reporter cassette is activated after Cre recombination (flip-excision, Fig. 3A). For the construction of the Cre-Flex plasmids, we used the pCHMWS-eGFP plasmid as a backbone (Geraerts et al., 2006). As illustrated in Fig. 3A, pairs of heterotypic loxP_loxm2 recombinase target sites were cloned respectively, upstream and downstream of eGFP using synthetic oligonucleotide adaptors. To enable efficient recombination, 46-bp spacers were inserted in between both lox sites. In this plasmid, eGFP was replaced by the coding sequence for eGFP-T2A-Fluc (Ibrahimi et al., 2009). All cloning steps were verified by DNA sequencing. Cre-Flex LVs were 
generated and produced by the Leuven Viral Vector Core essentially as described previously (Geraerts et al., 2005; Ibrahimi et al., 2009). Before the start of the in vivo experiments, the LV-Cre-Flex was validated in cell culture (Supplementary Fig. 1).

\section{Lentiviral vector injections}

Mice were anesthetized by ip injection of ketamine $(75 \mathrm{mg} / \mathrm{kg}$; Ketalar, Pfizer, Brussels, Belgium) and medetomidin (1 mg/kg; Domitor, Pfizer), and positioned in a stereotactic head frame (Stoelting, Wood Dale, Illinois, USA). Using a 30-gauge Hamilton syringe (VWR International, Haasrode, Belgium), $4 \mu \mathrm{L}$ of highly concentrated Cre-Flex LV was injected in the SVZ at a rate of $0.25 \mu \mathrm{L} / \mathrm{min}$. After injection of $2 \mu \mathrm{L}$, the needle was raised slowly over a distance of $1 \mathrm{~mm}$. After injection of the total volume the needle was left in place for an additional $5 \mathrm{~min}$ to allow diffusion before being slowly redrawn from the brain. SVZ injections were performed at the following coordinates relative to Bregma: anteroposterior $0.5 \mathrm{~mm}$, lateral $-1.5 \mathrm{~mm}$ and dorsoventral $-3.0-2.0 \mathrm{~mm}$. After surgery, anesthesia was reversed with an ip injection of atipamezol $(0.5 \mathrm{mg} / \mathrm{kg}$; Antisedan, Orion Pharma, Newbury, Berkshire, UK).

\section{Stroke models}

Anesthesia was provided with $2 \%$ isoflurane $/ \mathrm{O}_{2}$ gas anesthesia (Halocarbon Products Corporation, New Jersey, USA) through a facemask. The PT strokes were induced according to Vandeputte et al. (2011). Briefly, a vertical incision was made between the right orbit and the external auditory canal. Next, the scalp and temporalis muscle were retracted. After intravenous (iv) injection of the photosensitizer rose Bengal ( $20 \mathrm{mg} / \mathrm{kg}$; Sigma Aldrich, St Louis, USA) through the tail vein, photoillumination was performed for $5 \mathrm{~min}$. Photoillumination with green light (wave length, $540 \mathrm{~nm}$; band width, $80 \mathrm{~nm}$ ) was achieved using a xenon lamp (model L-4887; Hamamatsu Photonics, Hamamatsu City, Japan) with heat-absorbing and green filters. The irradiation at intensity $0.68 \mathrm{~W} / \mathrm{cm}^{2}$ was directed with a 3-mm optic fiber, the head of which was placed on the sensory motor cortex. Focal activation of the photosensitive dye resulted in local endothelial cell injury leading to microvascular thrombosis and circumscribed cortical infarctions (Watson et al., 1985). Sham-operated animals underwent the exact same procedure as the animals with a stroke, except for the 5 min photoillumination.

Transient occlusion of the middle cerebral artery (MCA) was done using the intraluminal filament technique previously described (Dirnagl and members of the MCAO-SOP group, 2009), although in our experiments the MCA was occluded for $20 \mathrm{~min}$.

\section{MR imaging}

For MRI data acquisition, mice were anesthetized with isoflurane (Halocarbon) in $\mathrm{O}_{2}$ (2.5\% for induction, $1.5-2 \%$ for maintenance). MR images were acquired using a Bruker Biospec 9.4 Tesla small animal MR scanner (Bruker BioSpin, Ettlingen, Germany; horizontal bore, $20 \mathrm{~cm}$ ) using a cross-coil setup consisting of a $7.2 \mathrm{~cm}$ linearly polarized resonator for transmission and a mouse head surface coil for signal reception as described before (Oosterlinck et al., 2011; Vandeputte et al., 2011). In brief, the following protocols were used: (a) $\mathrm{T}_{2}$ maps using a MSME sequence (10 echoes with $10 \mathrm{~ms}$ spacing, first TE $=10 \mathrm{~ms}$, TR $=2000 \mathrm{~ms}$, 16 nterlaced slices of $0.4 \mathrm{~mm}, 100 \mu \mathrm{m}^{2}$ in plane resolution); (b) $\mathrm{T}_{2}$ weighted MRI using a RARE sequence $\left(\mathrm{TE}_{\mathrm{eff}}=71 \mathrm{~ms}\right.$, TR $=1300 \mathrm{~ms}$, $100 \mu^{3}$ isotropic resolution) and (c) high-resolution $\mathrm{T}_{2}{ }^{*}$-weighted $3 \mathrm{D}$ FLASH (TR $=100 \mathrm{~ms}, \mathrm{TE}=12 \mathrm{~ms}, 100 \mu \mathrm{m}^{3}$ isotropic resolution). The location of the needle tract after stroke was measured with the Bruker Biospin software Paravision 5.x.

\section{In vivo bioluminescence imaging}

The mice were imaged in an IVIS 100 system (PerkinElmer, Waltham, MA, USA). Anesthesia was induced in an induction chamber with $2 \%$ isoflurane in $100 \%$ oxygen at a flow rate of $1 \mathrm{~L} / \mathrm{min}$ and maintained in the IVIS with a $1.5 \%$ mixture at $0.5 \mathrm{~L} / \mathrm{min}$. Before each imaging session, the mice were injected iv with $126 \mathrm{mg} / \mathrm{kg}$ D-luciferin (Promega, Leiden, the Netherlands) dissolved in PBS (15 mg/mL). Next, they were positioned in the IVIS and consecutive 1 or 2 min (depending on the experiment) frames were acquired until the maximum signal was reached. Data are reported as the total flux $\left(\mathrm{p} / \mathrm{s} / \mathrm{cm}^{2} / \mathrm{sr}\right)$ from a specific region of interest (ROI) of $12.5 \mathrm{~mm}^{2}$.

\section{Ex vivo bioluminescence imaging}

Immediately after in vivo BLI imaging, mice were sacrificed by cervical dislocation, decapitated and the brain was dissected. The brain was placed in an acrylic brain matrix (Harvard apparatus, Holliston, MA, USA) and sliced in 1.0 mm-thick sections. Next, these sections were imaged for $1 \mathrm{~min}$ in the IVIS.

\section{Immunohistochemistry}

Animals were sacrificed with an ip overdose $(15 \mu \mathrm{L} / \mathrm{g})$ of pentobarbital (Nembutal, CEVA Santé Animale, Libourne, France) and transcardially perfused with $4 \%$ paraformaldehyde (PFA) in PBS. Brains were removed and postfixed for $24 \mathrm{~h}$ with PFA. $50 \mu \mathrm{m}$ thick coronal sections were treated with $3 \%$ hydrogen peroxide and incubated overnight with the primary antibody, rabbit anti-eGFP (made in-house, 1:10000 (Baekelandt et al., 2003)) or a rabbit anti-Cre recombinase (1:3000 (Lemberger et al., 2007)), in 10\% normal swine serum and $0.1 \%$ Triton X-100. The sections were then incubated in biotinylated swine anti-rabbit secondary antibody (diluted 1:300; Dako, Glostrup, Denmark), followed by incubation with streptavidin horseradish peroxidase complex (Dako). Immune-reactive cells were detected by 3,3'-diaminobenzidine, using $\mathrm{H}_{2} \mathrm{O}_{2}$ as a substrate. For 5-bromo-2'deoxyuridine (BrdU) detection, sections were pre-treated for $30 \mathrm{~min}$ in $2 \mathrm{~N} \mathrm{HCl}$ at $37{ }^{\circ} \mathrm{C}$, blocked in $0.1 \mathrm{M}$ borate buffer for $20 \mathrm{~min}$, rinsed $3 \times 10$ min in PBS before incubation with rat anti-BrdU (1:400, Accurate chemical, NY, USA) in $10 \%$ horse serum, followed by incubation with biotinylated donkey anti-rat secondary antibody (Jackson ImmunoResearch Laboratories). The number of $\mathrm{eGFP}^{+}$cells was estimated with an unbiased stereological counting method, by employing the optical fractionator principle in a computerized system, as described previously (Baekelandt et al., 2002) (StereoInvestigator, MicroBright-Field, Magdeburg, Germany).

For immunofluorescent stainings, sections were treated with PBS$10 \%$ horse serum- $0.1 \%$ Triton X-100 for $1 \mathrm{~h}$. Next, sections were incubated overnight at $4{ }^{\circ} \mathrm{C}$ in PBS-0.1\% Triton X-100 with the following antibodies: chicken anti-eGFP (1:500, Aves labs, Tigard, OR) and rabbit anti-glial fibrillary acidic protein (GFAP) for astroglial cells and type B cells (1:500, Dako), goat anti-doublecortin (DCX) for migrating neuroblasts (1:200, Santa Cruz Biotechnology), or rabbit anti-neuronal nuclei (NeuN) for mature neurons (1:1000, EnCor Biotechnology Inc., Gainesville, FL, USA). The next day, sections were incubated with the appropriate mixture of the following fluorescently labeled secondary antibodies at room temperature for $2 \mathrm{~h}$ : donkey anti-chicken (FITC, 1:200, Jackson ImmunoResearch Laboratories), donkey anti-goat (Alexa 555, 1:400, Molecular Probes) or donkey anti-rabbit (Alexa $647,1: 400$, Molecular Probes). Next, the sections were washed in PBS$0.1 \%$ Triton X-100 and mounted with Mowiol. Fluorescence was detected with a confocal microscope (FV1000, Olympus) with a $488 \mathrm{~nm}$, a $559 \mathrm{~nm}$ and a $633 \mathrm{~nm}$ laser. The signal from each fluorochrome was collected sequentially. For the quantification of double and triple positive cells, all GFP ${ }^{+}$cells in the right SVZ, corpus callosum and stroke region (one section per animal) were analyzed at $40 \times$ using $z$-plane confocal 
microscopy with $1 \mu \mathrm{m}$ steps. All images shown correspond to projections of $18 \mu \mathrm{m}$ z-stacks, except Fig. $6 \mathrm{~F}$ which is a single focal plane. Brightness, contrast and background were adjusted equally for the entire image using 'brightness and contrast' controls in Image J.

\section{Statistics}

All statistical analyses were performed in Prism 5.0 (GraphPad Software). The statistical tests that were used are indicated in the figure legends. Data are represented as mean \pm standard error of the mean (s.e.m.). p-values are indicated as follows: ${ }^{*} \mathrm{p}<0.05,{ }^{* *} \mathrm{p}<0.01$, and *** $\mathrm{p}<0.001$.

\section{Results}

Nestin-CreER ${ }^{T 2} /$ Fluc mice show an increased BLI signal after stroke

To monitor a stroke-induced eNSC response with BLI we initially used a transgenic strategy, where Nestin-CreER ${ }^{\mathrm{T} 2}$ mice were crossbred with ROSA26-loxP-stop-loxP(L-S-L)-luciferase transgenic mice. In the resulting Nestin-CreER ${ }^{\mathrm{T} 2} /$ Fluc mice, Fluc expression is induced specifically in the nestin ${ }^{+}$eNSCs following administration of tamoxifen (Lagace et al., 2007). First, we monitored the migration of eNSC progeny from the SVZ to the OB with BLI in healthy adult Nestin-CreER ${ }^{\mathrm{T} 2} /$ Fluc mice. BLI was performed 1 week before and 1, 4, 8, 15 and 20 weeks after tamoxifen administration in healthy Nestin-CreER ${ }^{\mathrm{T} 2} /$ Fluc mice $(\mathrm{n}=5)$ or Cre-negative littermates $(\mathrm{n}=4)$. At all time points investigated, no distinct in vivo BLI signals could be detected in the neurogenic regions of Nestin-CreER ${ }^{\mathrm{T} 2} /$ Fluc mice and in Cre-negative littermates (Figs. 1A-C). Furthermore, there was no significant increase in BLI signal originating from the $\mathrm{OB}$ over time in Nestin-CreER ${ }^{\mathrm{T} 2} /$ Fluc mice (Figs. $1 \mathrm{~B}$, C). Although no differences in in vivo BLI signal could be detected, ex vivo BLI analysis showed a 2 to 3 fold higher BLI signal in the OB and SVZ of Nestin-CreER ${ }^{\mathrm{T} 2} /$ Fluc mice compared to Cre-negative littermates (Figs. 1 $D, E)$. This indicates that Fluc is indeed expressed in eNSCs of the SVZ and in the progeny arriving in the OB, as is evidenced by ex vivo BLI, but the number of labeled cells is too low for in vivo detection. The latter might be explained by a low neurogenic potential in the Nestin-CreER ${ }^{\mathrm{T} 2} /$ Fluc
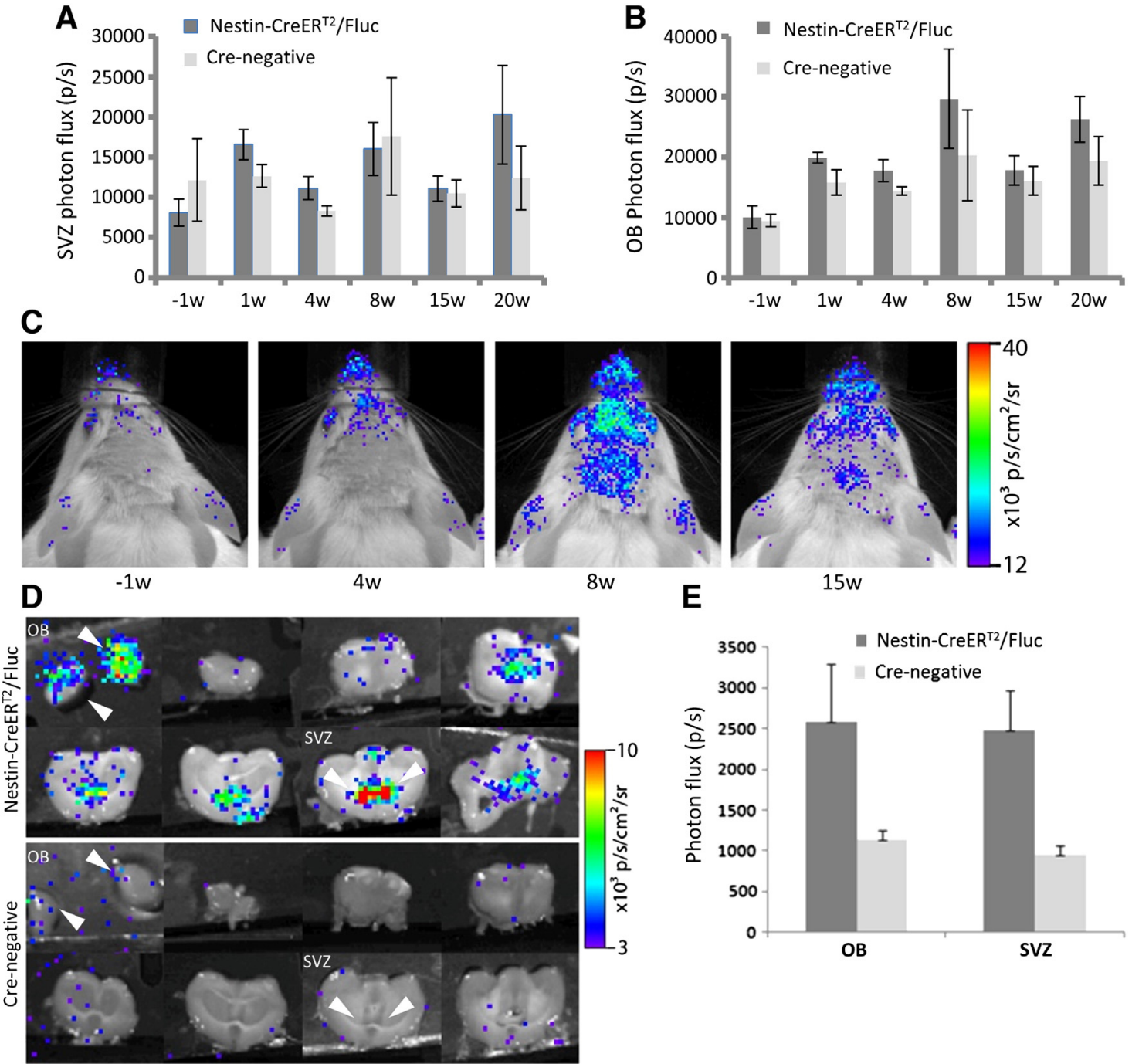

E
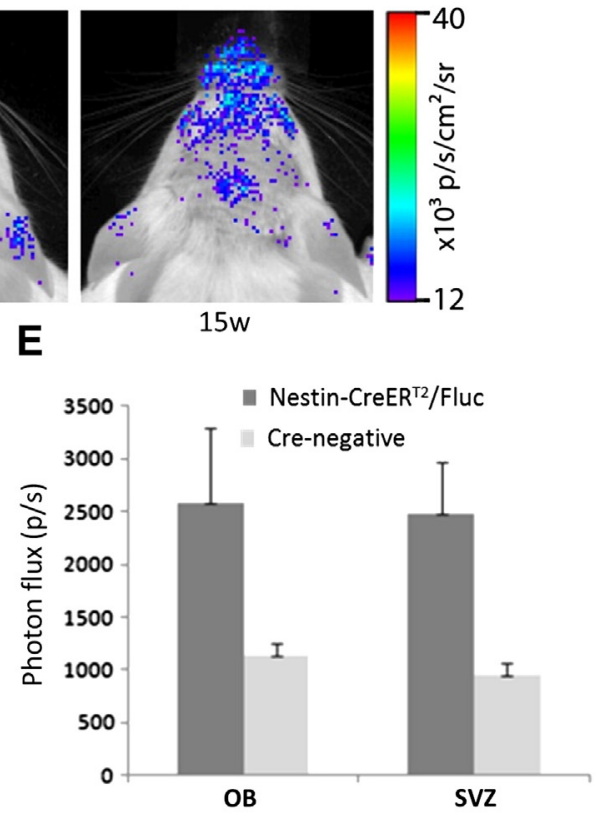

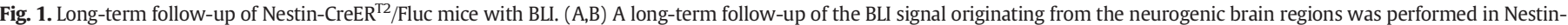

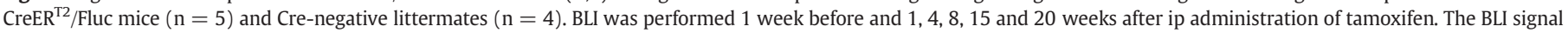

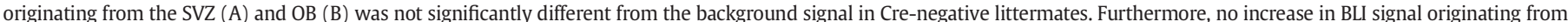

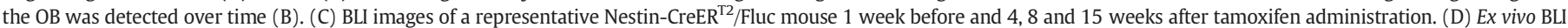

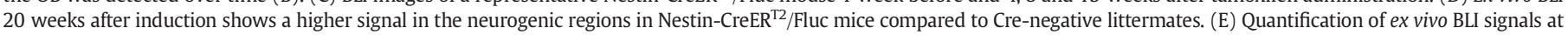

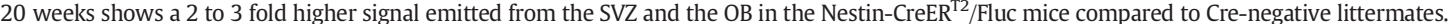


mice, since differences in neurogenic potential between mouse strains have been described (Kempermann et al., 1997). Therefore, we evaluated the neurogenic potential in Nestin-CreER ${ }^{\mathrm{T} 2} /$ Fluc mice and in agematched C57BL/6 mice using BrdU (Supplementary Fig. 2) and showed that proliferation in the SVZ and number of newborn neurons arriving in the OB was not different. In conclusion, neurogenesis in SVZ and migration to the $\mathrm{OB}$ could not be monitored with in vivo BLI in healthy adult Nestin-CreER ${ }^{\mathrm{T} 2} /$ Fluc mice.

Next, we investigated whether stroke-induced neurogenesis could be monitored in Nestin-CreER ${ }^{\mathrm{T} 2} /$ Fluc mice. Nine days after tamoxifen administration, mice either received a PT stroke in the right sensorimotor cortex $(n=8)$ or a sham treatment $(n=2)$ (Fig. 2A). Cre-negative littermates with stroke were included as controls $(n=3)$. BLI was performed one day prior to and 7, 15, 22 and 33 days after surgery. In Nestin-CreER ${ }^{\mathrm{T} 2} /$ Fluc mice receiving sham treatment and in Crenegative littermates receiving stroke, no in vivo BLI signal could be detected (Figs. 2B,C). However, in 6 out of 8 Nestin-CreER ${ }^{\mathrm{T}} /$ Fluc mice that received a stroke, a distinct BLI signal emerging from the stroke area was detected starting at day 7 (Figs. 2B,C), compared to the baseline scan before surgery, being $3.2 \pm 0.4$ fold higher at 7 days ( $p<0.001), 4.2 \pm 0.5$ fold higher at 15 days $(p<0.001), 2.1 \pm 0.4$ fold higher at 22 days $(\mathrm{p}<0.05)$ and $1.9 \pm 0.3$ fold higher at 33 days (not significant) after surgery (Fig. 2B). Ex vivo analysis was performed after 33 days and demonstrated in 3 out of 6 animals a BLI signal emerging from the stroke region, corroborating the in vivo measurements and excluding that the signal originated from the skin (Fig. 2D). Although the BLI signal emerging from the stroke area could result from accumulation of migrating SVZ progeny, alternatively, mature astrocytes in the infarction zone might have dedifferentiated upon injury, resulting in nestin and subsequent Fluc activity (Buffo et al., 2008). Thus, although a stroke-induced neurogenic response can be detected with in vivo BLI in Nestin-CreER ${ }^{\mathrm{T} 2} /$ Fluc mice, the exact origin of the BLI signal could not be identified.
Development and validation of conditional Cre-Flex LVs for specific eNSC labeling

To overcome this limitation, we engineered a viral vector-based system, containing a Cre-Flex cassette. The LV encodes a reporter cassette, here encoding eGFP and Fluc linked by a peptide 2A sequence, in reverse orientation relative to the promoter, that is only activated in cells expressing Cre recombinase (LV-Cre-Flex $><$ eGFP-T2A-Fluc; Fig. 3A). We injected LV-Cre-Flex $><$ eGFP-T2A-Fluc into Nestin-Cre transgenic mice, which express Cre recombinase under the control of the rat nestin promoter and enhancer, limiting Cre expression to eNSCs. As a result, eGFP and Fluc expression is specifically activated in eNSCs and their progeny. The use of 2A-like peptides results in equimolar expression of Fluc and eGFP reporter genes (Ibrahimi et al., 2009), enabling BLI and immunohistochemistry for eGFP to identify transduced cells in the same animal.

The LVs were injected in the SVZ of healthy adult Nestin-Cre mice $(n=9)$ to label the eNSCs and the migration of the progeny to the OB was monitored by BLI at 1, 8, 15, 20 and 27 weeks after injection (Figs. 3B,C). In line with earlier data (Reumers et al., 2008), a distinct BLI signal emerged from the $\mathrm{OB}$ at 8 weeks, which gradually increased over time being $3.2 \pm 0.3$ fold higher at 8 weeks (not significant), $4.3 \pm 0.8$ fold higher at 15 weeks ( $\mathrm{p}<0.01$ ), $5.1 \pm 1.1$ fold higher at 20 weeks $(\mathrm{p}<0.001)$ and $5.5 \pm 1.4$ fold higher at 27 weeks $(\mathrm{p}<0.001)$ compared to 1 week after injection (Figs. 3B,C). No BLI signal from the OB could be identified in WT mice 1 or 15 weeks after injection of the Cre-Flex LV $(\mathrm{n}=4)$ (Figs. 3B, C). Immunohistochemical detection of $\mathrm{Cre}^{+}$and $\mathrm{eGFP}^{+}$cells showed specific labeling of cells lining the ventricle wall and labeled eNSC progeny in the OB (Figs. 3D-E-F, respectively). In conclusion, the conditional LV-based labeling system combines specific and efficient labeling of the eNSC population of the SVZ with the possibility for immunohistochemical analysis of the transduced eNSCs and their progeny. Additionally, migration of the eNSC progeny to the OB could

\section{A}

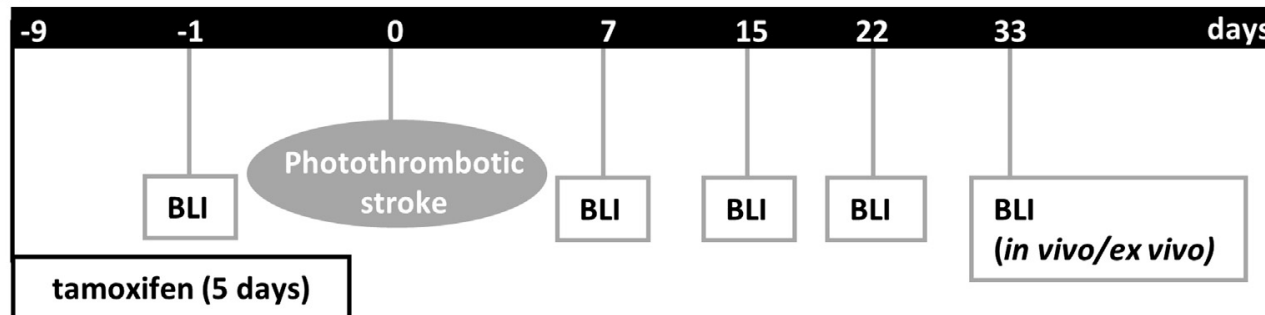

B

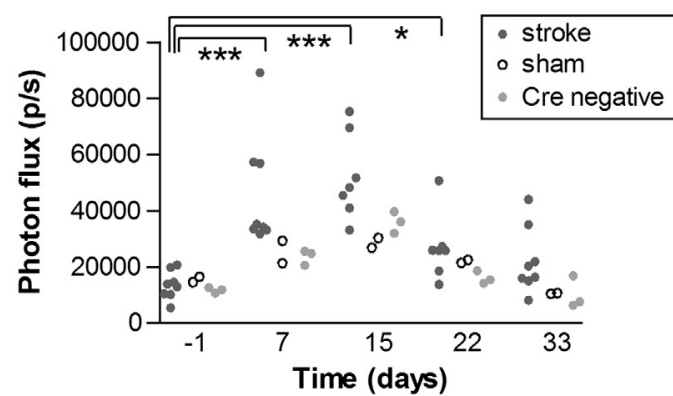

C

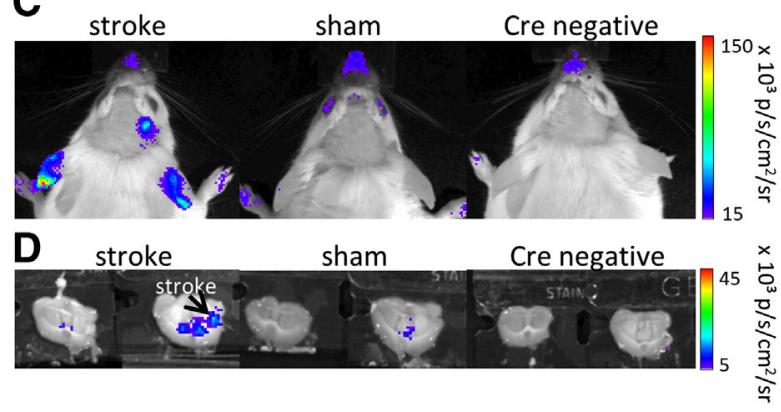

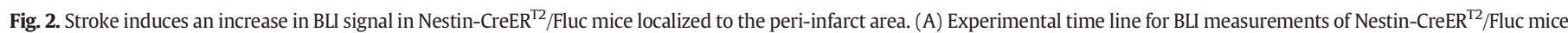

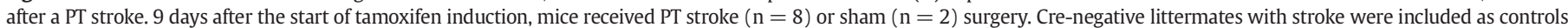

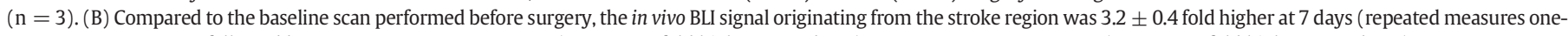

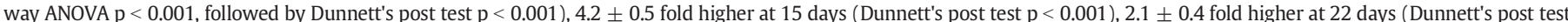

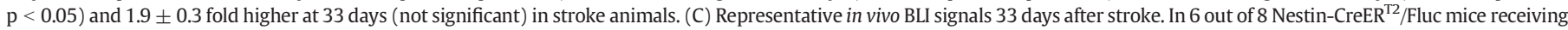

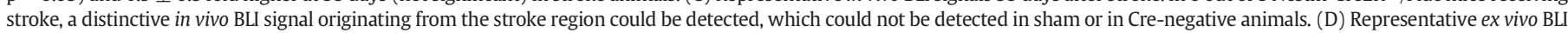
signals 33 days after stroke. In 3 of the 6 animals with an increased in vivo stroke BLI signal, an ex vivo BLI spot in the stroke region could be detected. 
A

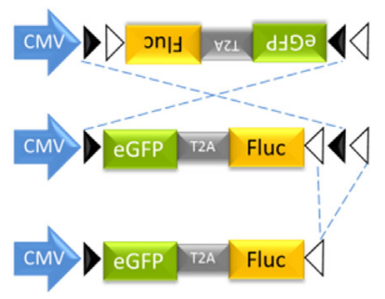

C

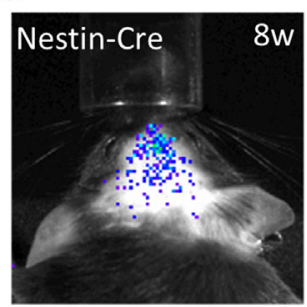

D

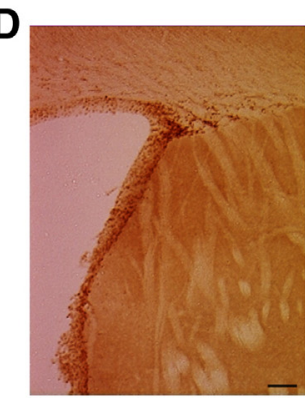

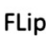

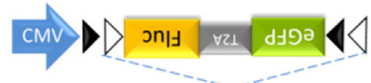

EXcision
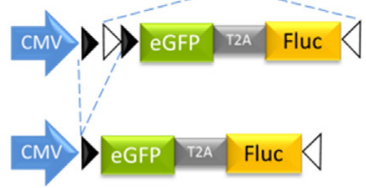

B

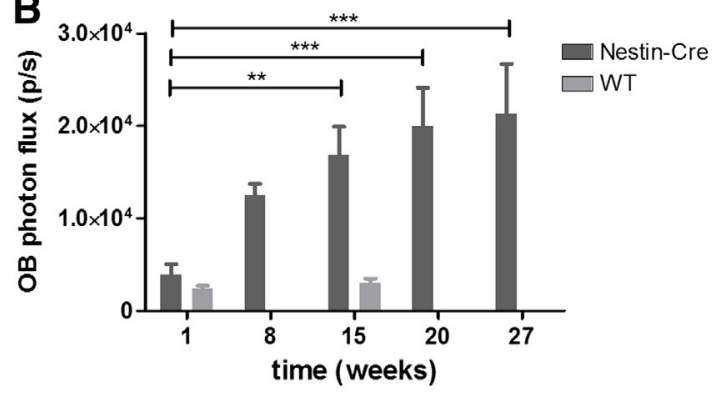

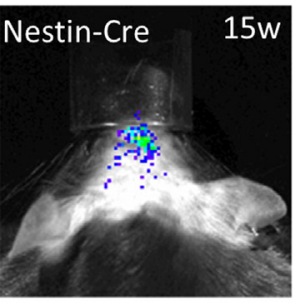

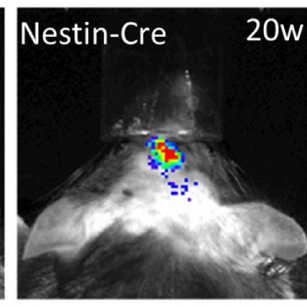

E

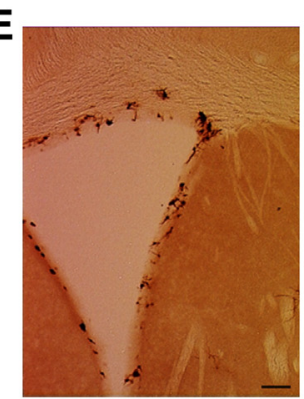

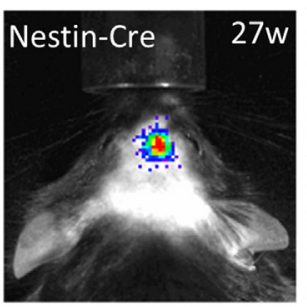
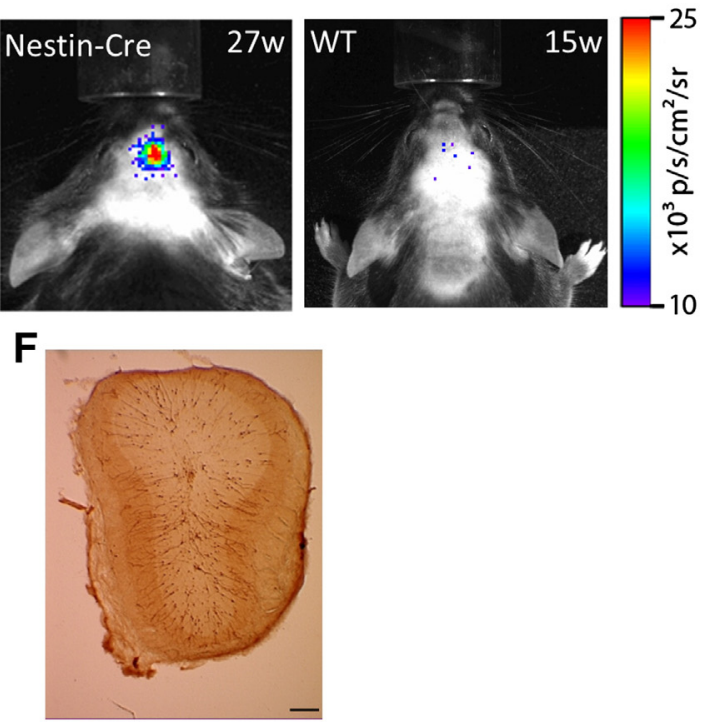

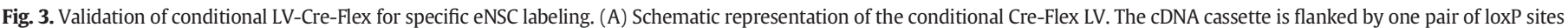

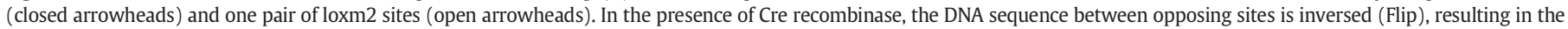

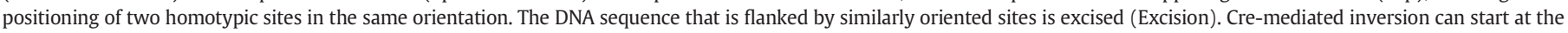

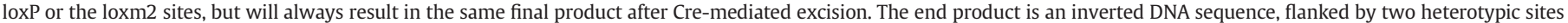

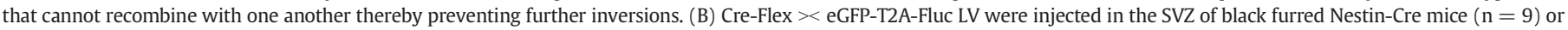

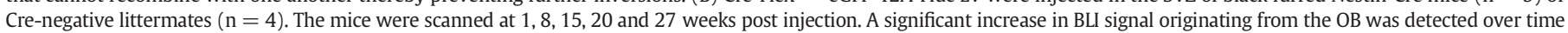

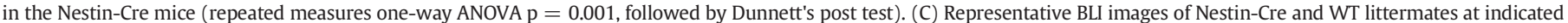

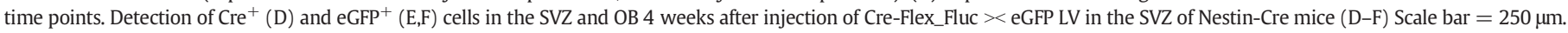

be monitored in vivo with BLI, which was not feasible in the NestinCreER $^{\mathrm{T} 2} /$ Fluc mice.

Stroke-induced neurogenic response in the SVZ is detected by BLI and histology

Cre-Flex LVs were applied to monitor the eNSC response after stroke (Fig. 4A). Adult Nestin-Cre mice were stereotactically injected with LVCre-Flex $><$ eGFP-T2A-Fluc into the right side of the SVZ. Seven days post injection, the animals received either a PT stroke in the right sensorimotor cortex $(n=21)$ or sham surgery $(n=9)$. Stroke lesions were monitored with MRI 2, 7 and 14 days after surgery (Fig. 4C). BLI measurements were performed 1 day before (baseline) and 2, 7, 14, 30 and 90 days after surgery (Figs. 4A,B,D). As a control, a Crenegative mouse was injected with the LV-Cre-Flex vector and received a PT stroke. It was monitored until 3 months after stroke, but no BLI signal could be detected (data not shown). At all time points investigated, the sham animals showed no difference in BLI signal compared to the baseline scan (Fig. 4D). However, mice with a PT stroke showed a $4.3 \pm 0.8$ fold increase in BLI signal at 2 days $(p<0.001)$, a $6.2 \pm 1.6$ fold increase at 7 days $(\mathrm{p}<0.01)$, a $7.5 \pm 3.3$ fold increase at 14 days $(\mathrm{p}<0.05)$ and a $6.4 \pm 3.5$ fold increase at 30 days (not significant) (Fig. 4D). At later time points, the stroke BLI signal decreased until 90 days after stroke.
The stroke-induced increase in BLI signal was corroborated by stereological quantification of the number of $\mathrm{eGFP}^{+}$cells in the SVZ, striatum, corpus callosum (CC) and peri-infarct area (Figs. 5A,B). Most eGFP ${ }^{+}$ cells were detected in the $\mathrm{CC}$, reaching to the stroke area. In sham animals, $2116 \pm 209 \mathrm{eGFP}^{+}$cells $(\mathrm{n}=7)$ were counted and this number did not change over time. In animals receiving stroke surgery, the number of eGFP ${ }^{+}$cells was significantly higher at 2 days $(4123 \pm 674$, $\mathrm{p}<0.05, \mathrm{n}=7$ ), 7 days ( $5407 \pm 290, \mathrm{p}<0.05, \mathrm{n}=2$ ) and 14 days ( $4610 \pm 222, \mathrm{p}<0.05, \mathrm{n}=4$ ) after stroke, compared to sham animals (Fig. 5B). 90 days after stroke, the number of eGFP ${ }^{+}$cells decreased and was significantly lower $(2382 \pm 375, \mathrm{p}<0.05, \mathrm{n}=7)$ compared to 7 and 14 days after stroke, corroborating the results obtained by BLI.

To ensure that the $\mathrm{eFF}^{+}$cells originate from labeled eNSCs and not from reactive astrocytes that upregulate their nestin promoter and thus Cre upon injury, Cre expression was analyzed 2 days after stroke (Supplementary Figs. 3A,B). There was no Cre upregulation in the ipsilateral SVZ and CC compared to the contralateral hemisphere (Supplementary Fig. 3A), whereas Cre-positive cells with astrocyte-like morphology were detected in close proximity of the stroke lesion (Supplementary Fig. 3B). These cells were mainly present in the cortex on the dorsal side of the lesion and to a lesser extent on the lateral side of the lesion. Since the Cre-Flex LVs were injected in the SVZ, which is physically distant from the stroke region, and since the Cre-Flex LVs specifically label cells in the SVZ (Fig. 3E), it is unlikely that these distant reactive astrocytes were labeled directly via viral vector injection. Taken together, 

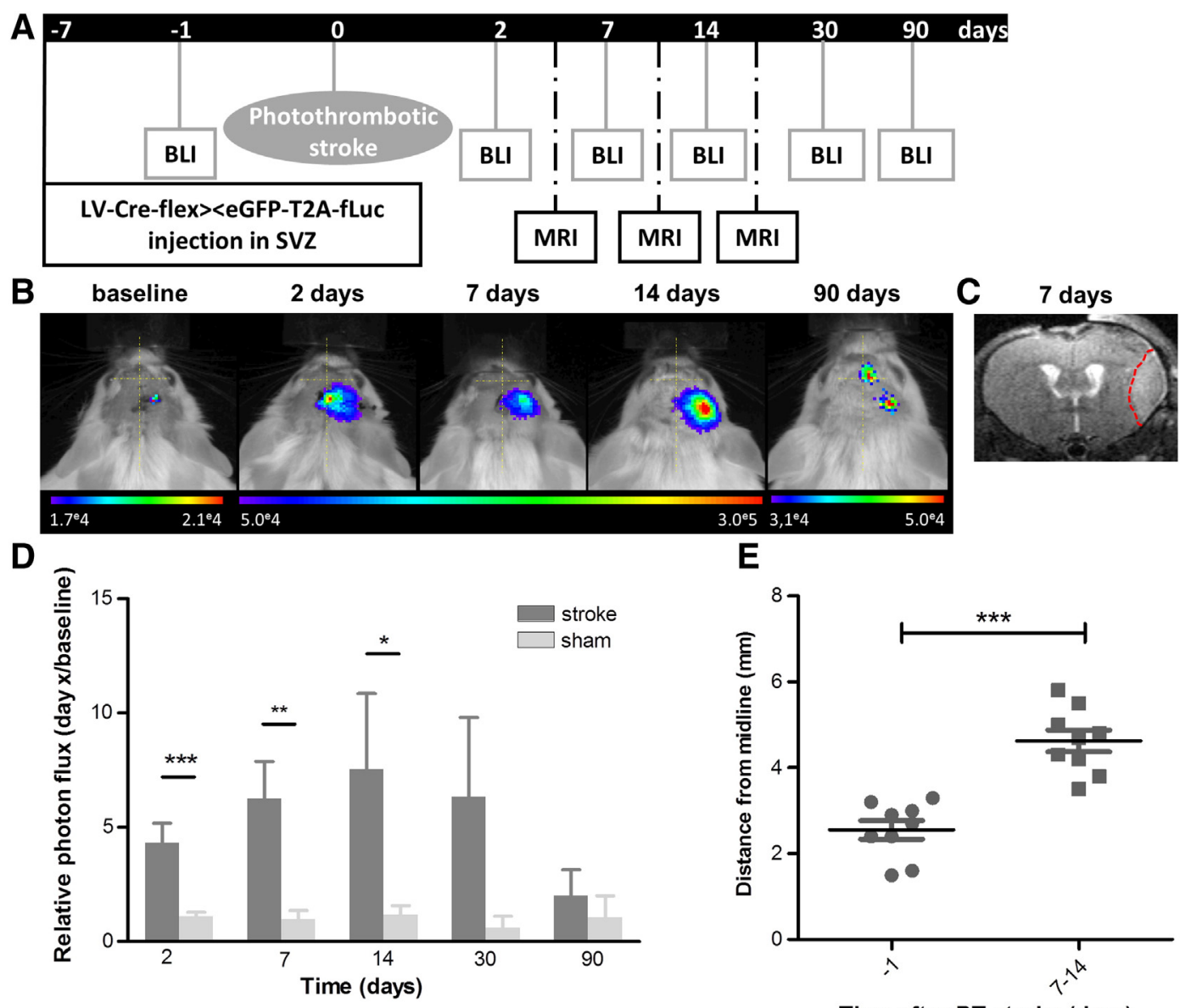

Time after PT stroke (days)

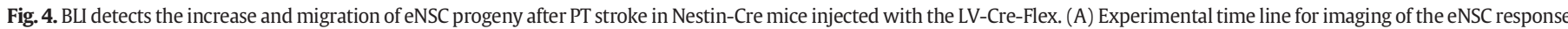

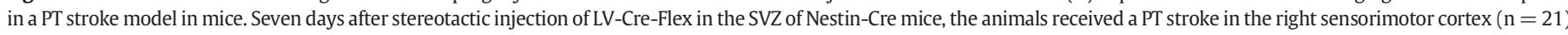

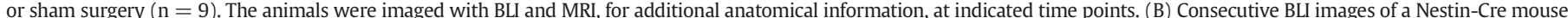

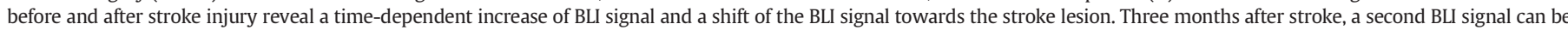

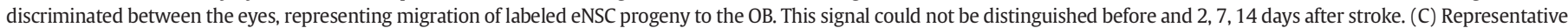

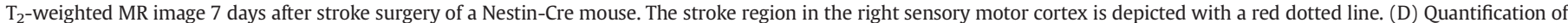

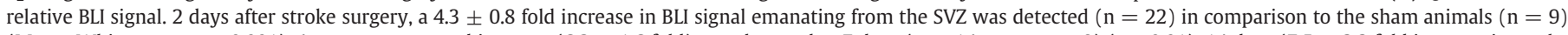

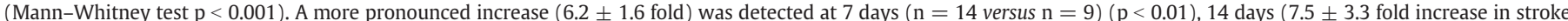

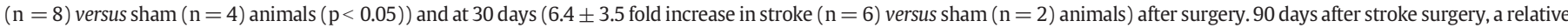

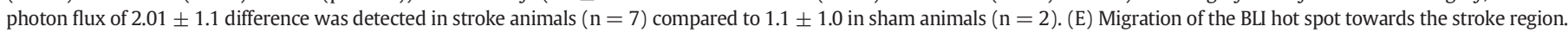

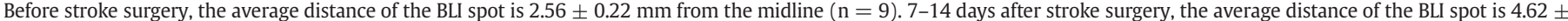
$0.25 \mathrm{~mm}$ from the midline $(\mathrm{n}=9, \mathrm{t}$-test $\mathrm{p}<0.001$ ).

the Cre-Flex LV allowed non-invasive monitoring of a stroke-induced transient increase in the number of $\mathrm{eGFP}^{+}$cells, which originated from labeled eNSCs in the SVZ.

In vivo BLI reveals eNSC migration to the area of infarction and OB following PT stroke

Long-term BLI follow-up of stroke animals not only revealed a transient increase in BLI signal, but also a clear shift of the BLI signal towards the stroke lesion was apparent (Fig. 4B). To estimate the migration of the BLI signal after stroke, the distance between the BLI hot spot and the midline was determined (Fig. 4E). Before stroke surgery, a unifocal signal originating from the site of injection was detected, which corresponds to labeled cells in the SVZ (average distance of $2.56 \pm$ $0.22 \mathrm{~mm}$ from midline). Two days after stroke, a small shift of the BLI signal towards the contralateral hemisphere was evident (Fig. 4B), probably due to the induction of edema as was detected by MRI (Supplementary Fig. 4A). At 1 and 2 weeks after stroke, a significant shift of the BLI spot towards the stroke region was observed in 9 out of 10 animals (average distance of $4.62 \pm 0.25 \mathrm{~mm}$ from midline, $\mathrm{p}<0.001$ compared to baseline) (Figs. 4B,E), suggesting migration of the eNSC progeny towards the stroke area. In the sham-operated animals no shift was detected at any of the time points (data not shown). Since dynamic changes of edema or changes in ventricle size due to loss of viable brain tissue might affect the location of the BLI signal, the animals were also imaged with MRI on the same day of the BLI (Fig. 4A). The needle tract was used as a reference and its shift due to edema formation or changes in ventricle size was monitored (Supplementary Figs. 4A,B). The needle tract shift 14 days after stroke compared to the time of injection was $0.39 \pm 0.04 \mathrm{~mm}(\mathrm{n}=9)$, which was considerably smaller than the shift of the BLI signal $(2.06 \mathrm{~mm})$. Although a small enlargement of the ventricles was detected in the animals with a PT stroke, its effect on the migration of BLI signal was limited.

Since most studies have investigated stroke-induced neurogenesis in models of middle cerebral artery occlusion (MCAO) (Parent et al. 2002; Thored et al., 2007), a small experiment where animals received either MCAO $(n=4)$ or sham surgery $(n=3)$ was performed (Supplementary Fig. 5). The MCAO model provides MCA territory infarctions, involving the striatum and the frontoparietal cortex, after the insertion of a monofilament that blocks the origin of MCA, whereas the PT stroke model involves the intravenous administration of a photosensitive dye followed by laser irradiation of any exposed region of the skull. 
A

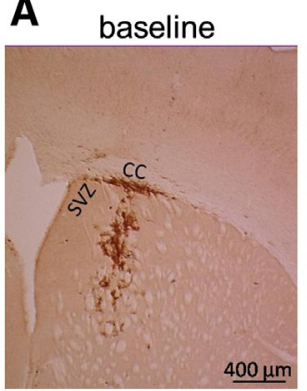

B

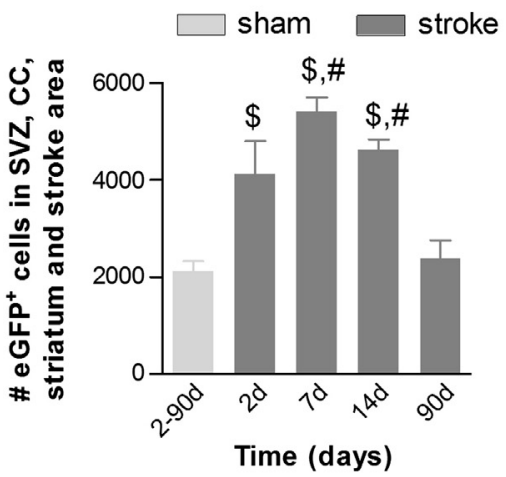

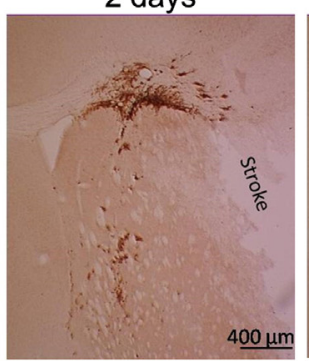

C

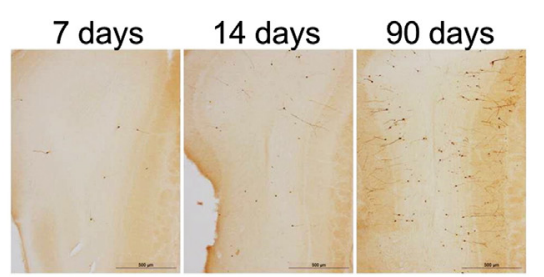

7 days

14 days

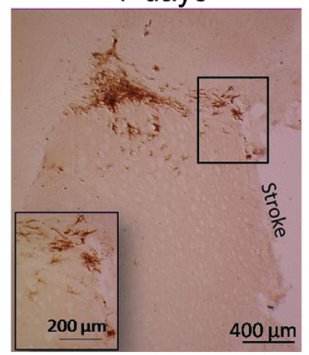

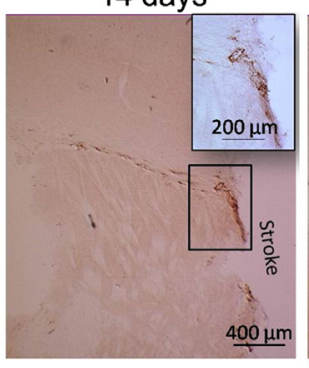

90 days

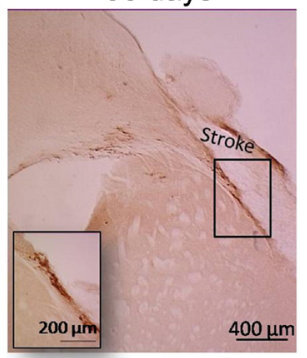

D

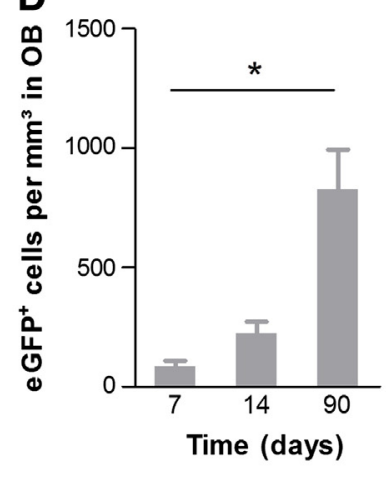

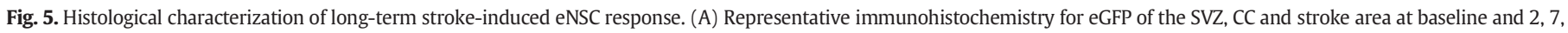

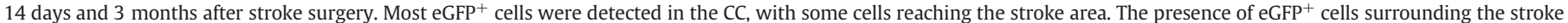

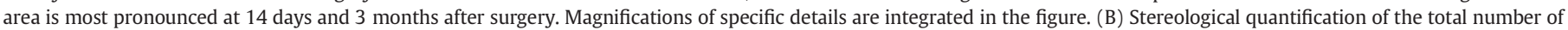

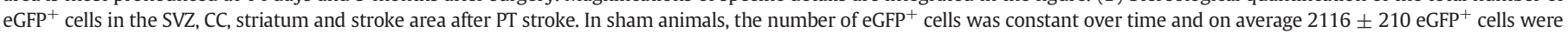

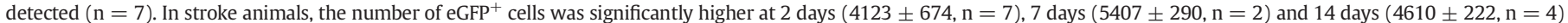

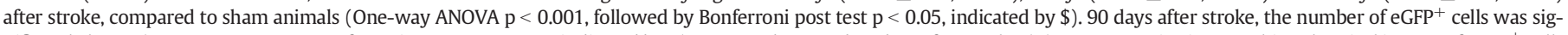

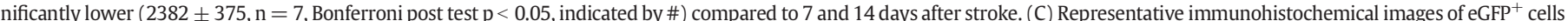

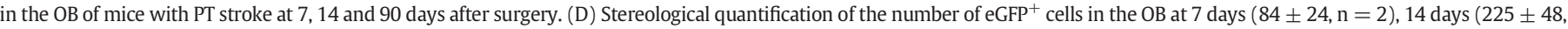

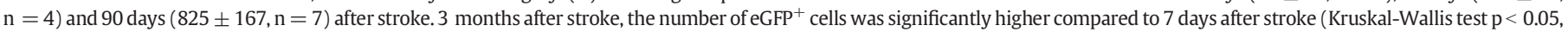

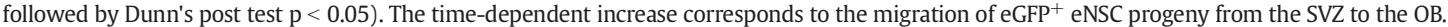

Although a 5 fold increase in BLI signal was detected over time in the animal with the largest MCAO stroke lesion, there was no re-location of the BLI signal, most likely due to the large stroke size and its location, which restrains the migration and localization of the labeled cells within a region of the ischemic striatum (Ohab and Carmichael, 2008).

In the group receiving PT stroke, long-term BLI follow-up revealed a clear BLI signal between the eyes in 5 out of 8 animals at 3 months after stroke, in line with migration of eNSC progeny to the OB (Fig. 4B). The origin of BLI signal emerging from the $\mathrm{OB}$ was corroborated histologically by a gradual increase in the number of $\mathrm{eGFP}^{+}$cells in the OB over time, being $2.7 \pm 0.6$ fold higher at 14 days (not significant) and $12.8 \pm 2.0$ fold higher $(\mathrm{p}<0.05)$ at 90 days compared to 7 days after stroke surgery (Figs. 5C,D). These results provide additional evidence that the LV-CreFlex specifically labeled the eNSCs in the SVZ.

In conclusion, injection of LV-Cre-Flex in the SVZ of Nestin-Cre mice allowed monitoring both the migration of eNSC progeny from the SVZ to the stroke region and to the $\mathrm{OB}$ with BLI.

eNSC progeny differentiates into astrocytes and neurons in the peri-infarct region

Since injection of LV-Cre-Flex in Nestin-Cre mice results in the expression of Fluc and eGFP in the eNSCs and their progeny, a detailed histological analysis of the transduced cell population and its progeny can be performed. In animals killed 90 days after PT stroke, light producing cells (152 $\pm 30 \mathrm{eGFP}^{+}$cells counted per animal, $\mathrm{n}=3$ ) were identified by double and triple immunofluorescence stainings (eGFP in combination with GFAP or DCX and NeuN (Fig. 6)). In the SVZ and the CC, $77 \pm 7 \%$ of eGFP $^{+}$cells were $\mathrm{GFAP}^{+}$eNSCs and astrocytes, $8 \pm 2 \%$ were $\mathrm{DCX}^{+}$migrating neuroblasts and $<1 \%$ were $\mathrm{NeuN}^{+}$mature neurons (Figs. 6A,C,E). A different pattern of cellular phenotypes was detected in the peri-infarct region: $36 \pm 5 \%$ of $\mathrm{eGFP}^{+}$cells were $\mathrm{GFAP}^{+}$astrocytes, $13 \pm 11 \%$ were $\mathrm{DCX}^{+}$migrating neuroblasts, $5 \pm$ $3 \%$ were $\mathrm{DCX}^{+} \mathrm{NeuN}^{+}$immature neurons and $21 \pm 16 \%$ were $\mathrm{NeuN}^{+}$ mature neurons (Figs. 6B,D,E). Evaluation of differentiation into mature neurons, displayed a high inter-animal variability, with one animal showing $50 \%$ of $\mathrm{eGFP}^{+}$cells co-expressing NeuN in the peri-infarct region, while the other two animals showed less than $10 \%$ coexpression. In the first animal, some $\mathrm{eGFP}^{+}$neurons showed long dendrites covered with many spines (Fig. 6F). These data indicate that the labeled eNSCs in the SVZ gave rise to progeny that migrated towards the stroke region where they eventually differentiated into both astrocytes and mature neurons.

\section{Discussion}

Detailed knowledge of the biological role and potential of eNSCs is of great importance for the success of neuro-regenerative therapies in different neurological disorders, including stroke. Therefore, development of non-invasive methods to monitor and study proliferation, migration and survival of eNSCs and their progeny in the same animal over time is crucial. The main advantage of cell tracking via BLI is the high sensitivity, especially when cells are located in superficial tissues (Massoud and Gambhir, 2003). The present study demonstrates non-invasive imaging of the eNSC response after PT stroke in a mouse model using BLI. First, we generated double transgenic Nestin-CreER ${ }^{\mathrm{T} 2} /$ Fluc mice, in which Fluc expression is induced in the eNSCs after tamoxifen administration. After stroke, these mice showed an increase in BLI signal in vivo $(\mathrm{n}=$ $6 / 8$ ) and ex vivo $(\mathrm{n}=3 / 8)$ originating from the stroke lesion (Figs. $2 \mathrm{~B}$, $\mathrm{C}$ ). The discrepancy in efficiency between the in vivo and ex vivo results 


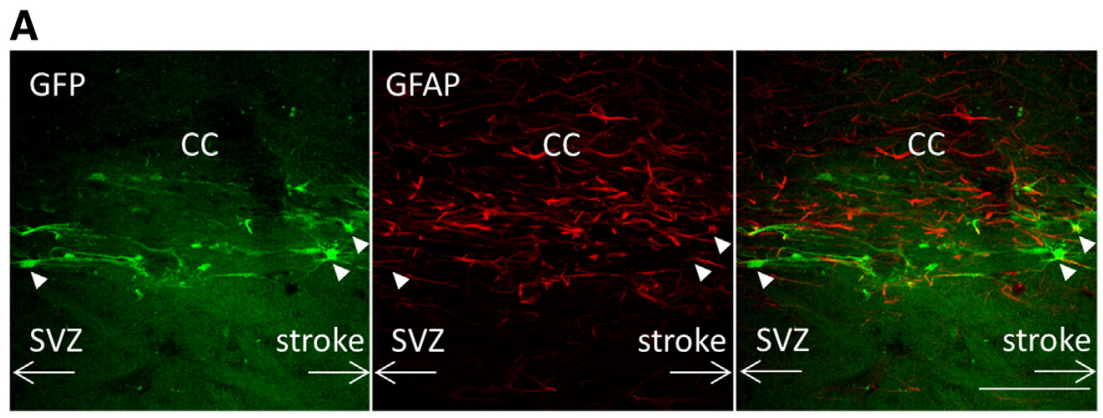

B
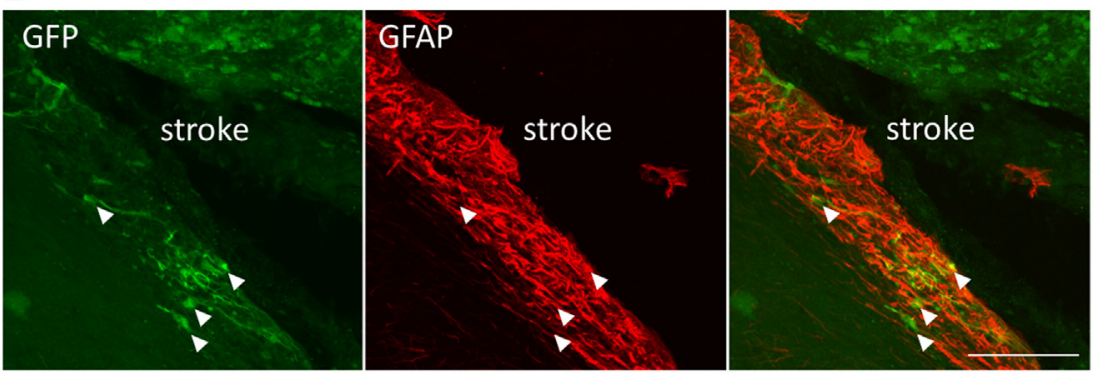

C

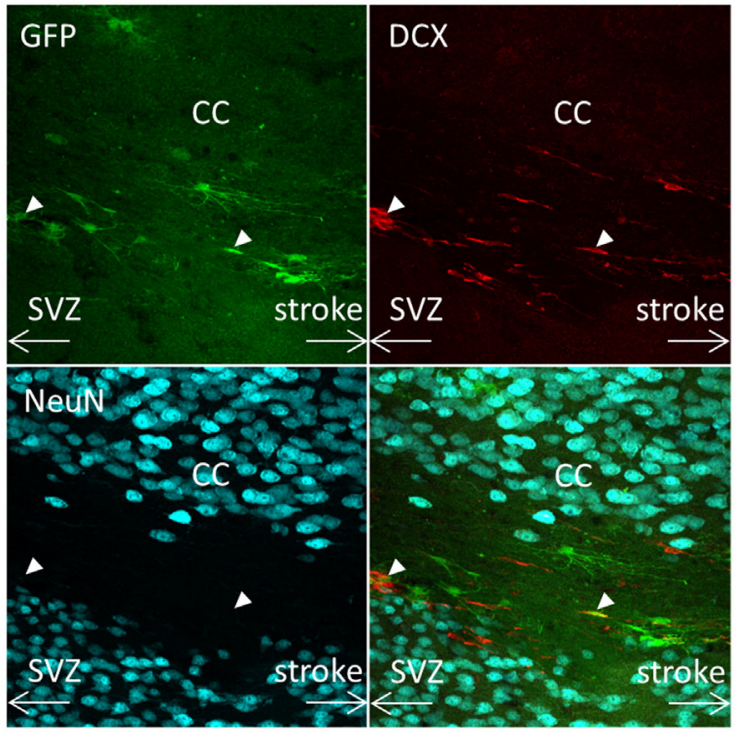

D

E

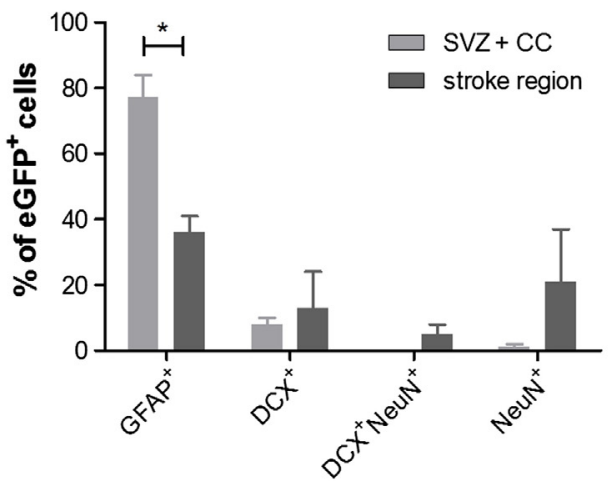

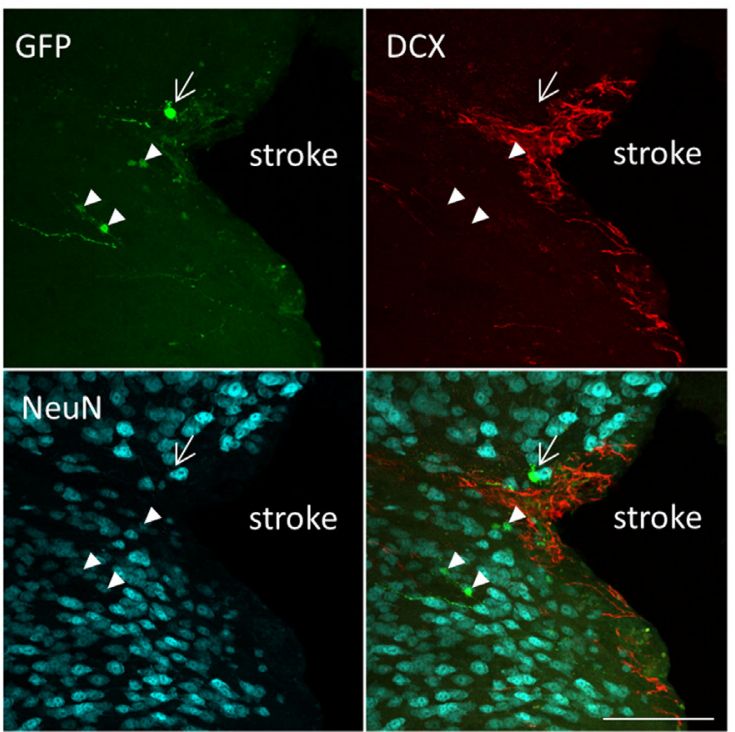

F

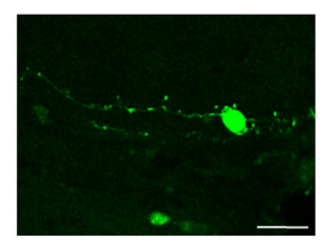

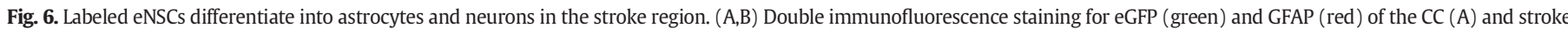

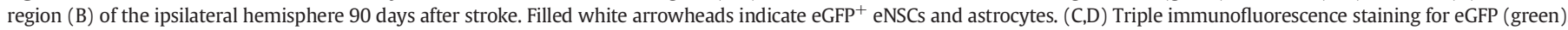

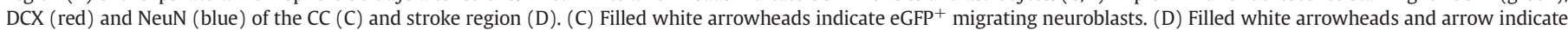

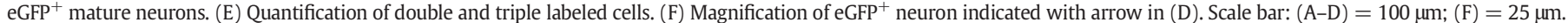


can be explained by technical issues, such as the time required to dissect the brain tissue immediately after sacrifice, which causes differences in oxygenation status of the tissue and enzymatic activity (Deroose et al., 2006). In the latter model it was impossible to define the origin of the cells giving rise to the BLI signal emerging from the stroke area, which might either originate from accumulation of migrating SVZ progeny or from dedifferentiation of local mature astrocytes upon injury, resulting in nestin and subsequently, Fluc expression (Buffo et al., 2008). Moreover, although Fluc is expressed in eNSCs of the SVZ and eventually in the progeny arriving in the $\mathrm{OB}$, as was evidenced by ex vivo BLI (Figs. $1 \mathrm{D}, \mathrm{E})$, the number of labeled cells or the expression level of Fluc per cell was too low for in vivo detection (Figs. $1 \mathrm{~A}-\mathrm{C}$ ). In this way, the effect of stroke on the neurogenic process towards the $\mathrm{OB}$ could also not be monitored.

In a second approach, we circumvented these drawbacks by devising conditional Cre-Flex LVs to inject in the SVZ of Nestin-Cre mice. Specific induction of Fluc and eGFP in the eNSCs and their progeny allows both BLI and immunohistochemical characterization of the neurogenic process. In contrast to the first approach using double transgenic mice, in vivo BLI signals from the SVZ and eventually from the OB could be detected (Fig. 3C), most probably due to the higher Fluc expression levels. Induction of a PT stroke resulted in a significant gradual increase in BLI signal between 2 days and 2 weeks after surgery (Figs. 4B,D). The latter was underscored by an increase in $\mathrm{eGFP}^{+}$cells in the SVZ, striatum, CC and stroke region (Fig. 5B). Subsequently, the BLI signal and the number of $\mathrm{eGFP}^{+}$cells decreased to background levels at 3 months after stroke. This transient increase in eNSC progeny is in accordance with two studies describing a transient increase in the proliferation and migration of eNSCs following stroke or brain trauma, detected by histology using cell type-specific markers (Parent et al., 2002) or by retroviral labeling of SVZ cells (Goings et al., 2004). Parent et al. showed that the number of BrdU-labeled cells was lower 5 weeks after stroke compared to previous time points, suggesting that many of the newly generated cells died (Parent et al., 2002).

In Nestin-Cre mice injected with the Cre-Flex LV, a clear relocalization of the BLI signal towards the stroke area was detected between 1 and 2 weeks after stroke surgery. This was confirmed histologically by $\mathrm{eGFP}^{+}$cells moving closer towards the ischemic lesion over time (Figs. 4B and 5A). The 1-2 weeks time frame of this migration is in agreement with the work of Ohab et al. who detected $\mathrm{GFP}^{+}$cells, originating from the SVZ, in the peri-infarct cortex 7 and 14 days after stroke (Ohab et al., 2006). When monitoring eNSC migration after stroke with BLI, we encountered some technical hurdles. First, edema formation causes a shift of the midline, resulting in a slight apparent re-location of the BLI spot towards the contralateral hemisphere, complicating detection of eNSC migration towards the lesion at early time points. Second, changes in ventricle size, due to tissue degeneration after stroke may confound the imaging results (Karki et al., 2010). Therefore, we combined BLI with MRI, which has a high spatial resolution and gives better insight in alterations of the anatomical structure of the brain.

Since labeled cells express a fluorescent reporter (eGFP) in addition to the bioluminescent Fluc reporter, the origin and identity of light emitting cells could be determined by immunohistochemical stainings. Ninety days after stroke, labeled eNSC progeny differentiated into both astrocytes and mature neurons, demonstrating the multipotency of eNSCs upon stroke injury (Arvidsson et al., 2002; Goings et al., 2004; Parent et al., 2002). The majority of $\mathrm{eGFP}^{+}$labeled cells in the SVZ, CC and the stroke region expressed GFAP, corroborating astrocytic differentiation of eNSC progeny after cortical injury (Goings et al., 2004; Holmin et al., 1997). In addition, using tamoxifen-inducible Nestin$\mathrm{CreER}^{\mathrm{T} 2}$ :R26R-YFP reporter mice, Li et al. demonstrated that $45 \%$ of eNSC progeny co-expressed GFAP 6 weeks after MCAO, indicating a significant gliogenic component (Li et al., 2010).

Since stroke injury might induce nestin expression in reactive astrocytes (Buffo et al., 2008; Shimada et al., 2010; Sirko et al., 2013) or in vasculature-associated cells in the ischemic core (Shin et al., 2013), one could question the source of the eGFP ${ }^{+}$cells located around the ischemic lesion. However, it has been well described that reactive astrocytes are mainly present in the close vicinity of the stroke region. Unbiased stereological quantifications of astrocyte proliferation, a hallmark of reactive gliosis, showed that astrocytes respond to stroke injury in a spatially graded way (Barreto et al., 2011). The authors showed that most astrocyte proliferation occurs within $200 \mu \mathrm{m}$ of the edge of the infarct. In addition, nestin upregulation of reactive astrocytes has been shown to be confined to the peri-infarct region, or to clearly demarcate the lesion boundary (Li and Chopp, 1999; Shimada et al., 2010). Since we injected the Cre-Flex LV in the SVZ, which is physically distant from the stroke region, and since we did not detect any changes in Cre expression in the SVZ or CC, we consider it unlikely to label local reactive astrocytes around the stroke region. Another indication that argues against local reactive astrocytes as the main origin of labeled cells concerns the localization of the BLI signal: if the 4.3 fold increase in BLI signal two days after stroke would be caused by labeling of reactive astrocytes, one would expect appearance of a new BLI spot emerging from the stroke region, or a shift of the existing SVZ BLI spot towards the stroke region. However, we show that this is not the case and that there is even a small shift of the original SVZ BLI spot towards the contralateral side (Fig. 4B). A clear migration of the BLI spot towards the stroke region was only apparent after 7-14 days after stroke. Our data strongly suggest migration of the progeny of transduced eNSCs via the $\mathrm{CC}$ to the stroke lesion. The increase in BLI signal between the eyes and the corresponding increase in the number of eGFP ${ }^{+}$cells in the OB over time, points to the migration of labeled eNSC progeny from the SVZ to the OB, proving that the eNSCs in the SVZ were labeled by the Cre-Flex LV. Several research groups have shown a reduction or diversion of normal neuroblast migration from the SVZ to the OB at early time points after cortical lesion or stroke (Goings et al., 2004; Ohab et al., 2006). The Cre-Flex LV technology will allow longitudinal non-invasive imaging of the effects of brain lesions on rostral migration.

The present study focuses on the response of SVZ-derived Nestin ${ }^{+}$ eNSCs on stroke injury. However, none of the eNSC markers currently available exclusively labels eNSCs and evidence emerges suggesting eNSC heterogeneity both in the SVZ (Giachino et al., 2013) and the SGZ (Bonaguidi et al., 2012; DeCarolis et al., 2013). It would therefore be interesting to apply the Cre-Flex LVs in different transgenic mice to compare the contribution of different progenitor populations to the stroke-induced neurogenic response (Dhaliwal and Lagace, 2011). In addition, the Cre-Flex LVs might also be used to study eNSC response in other disease models (Guglielmetti et al., 2013).

In conclusion, we developed a novel technique based on conditional Cre-Flex LVs that allows non-invasive imaging of the stroke-induced eNSC response in living mice with BLI. In addition, this new technique enables fate mapping of the eNSC progeny after stroke by immunohistochemistry. Our BLI and histological data are consistent with the prevailing hypothesis that stroke induces a transient increase in proliferation in the SVZ, a targeted migration of eNSC progeny towards the stroke region and differentiation in both astrocytes and neurons. For this reason, we believe that this technology may facilitate preclinical validation of neuro-regenerative strategies in rodent stroke models.

Supplementary data to this article can be found online at http://dx. doi.org/10.1016/j.nbd.2014.05.014.

\section{Conflict of interest statement}

The authors declare that they have no conflict of interest.

\section{Acknowledgments}

The authors thank the Leuven Viral Vector Core for the construction and production of LV and Prof. Johan Hofkens (Molecular Imaging and Photonics, KU Leuven) for the use of the confocal laser-scanning microscope. The authors are grateful to Ann Van Santvoort for support with 
the MRI scanning. Caroline Vandeputte was financially supported by the Institute for the Promotion of Innovation through Science and Technology in Flanders (IWT Vlaanderen) and by the KU Leuven program financing IMIR (In vivo Molecular Imaging Research; pf/10/017). SarahAnn Aelvoet is a doctoral fellow of the IWT Vlaanderen. Tracy Farr is a recipient of an Alexander-von-Humboldt fellowship. Koen Van Laere is senior clinical research fellow of the FWO Vlaanderen. This work was funded by the SBO-IWT-060838 Brainstim, the FWO project G.0484.08, the EC-FP6 network DiMI (LSHB-CT-2005-512146), EC-FP7/2007-2013 project, HEALTH-F2-2011-278850 (INMiND), EU 7th Framework (HEALTH-F2-2012-279017/TargetBrain) and by the Leuven University grants: MoSAIC CoE (Molecular Small Animal Imaging Center, Center of Excellence): EF/05/008 and SCIL PF/10/019.

\section{References}

Altman, J., 1962. Are new neurons formed in the brains of adult mammals? Science 135 1127-1128.

Altman, J., 1963. Autoradiographic investigation of cell proliferation in the brains of rats and cats. Anat. Rec. 145, 573-591.

Alvarez-Buylla, A., Garcia-Verdugo, J.M., 2002. Neurogenesis in adult subventricular zone. J. Neurosci. 22, 629-634.

Arvidsson, A., Collin, T., Kirik, D., Kokaia, Z., Lindvall, O., 2002. Neuronal replacement from endogenous precursors in the adult brain after stroke. Nat. Med. 8, 963-970. http://dx.doi.org/10.1038/nm747.

Baekelandt, V., Claeys, A., Eggermont, K., Lauwers, E., De Strooper, B., Nuttin, B., Debyser, Z., 2002. Characterization of lentiviral vector-mediated gene transfer in adult mouse brain. Hum. Gene Ther. 13, 841-853. http://dx.doi.org/10.1089/10430340252899019.

Baekelandt, V., Eggermont, K., Michiels, M., Nuttin, B., Debyser, Z., 2003. Optimized lentiviral vector production and purification procedure prevents immune response after transduction of mouse brain. Gene Ther. 10, 1933-1940. http://dx.doi.org/10. 1038/sj.gt.3302094.

Barreto, G.E., Sun, X., Xu, L., Giffard, R.G., 2011. Astrocyte proliferation following stroke in the mouse depends on distance from the infarct. PLoS ONE 6, e27881. http://dx.doi. org/10.1371/journal.pone.0027881.

Bonaguidi, M.A., Song, J., Ming, G., Song, H., 2012. A unifying hypothesis on mammalian neural stem cell properties in the adult hippocampus. Curr. Opin. Neurobiol. 22, 754-761. http://dx.doi.org/10.1016/j.conb.2012.03.013.

Buffo, A., Rite, I., Tripathi, P., Lepier, A., Colak, D., Horn, A.-P., Mori, T., Götz, M., 2008. Origin and progeny of reactive gliosis: a source of multipotent cells in the injured brain. Proc. Natl. Acad. Sci. U. S. A. 105, 3581-3586. http://dx.doi.org/10.1073/pnas. 0709002105.

Collin, T., Arvidsson, A., Kokaia, Z., Lindvall, O., 2005. Quantitative analysis of the generation of different striatal neuronal subtypes in the adult brain following excitotoxic injury. Exp. Neurol. 195, 71-80. http://dx.doi.org/10.1016/j.expneurol.2005.03.017.

Couillard-Despres, S., Finkl, R., Winner, B., Ploetz, S., Wiedermann, D., Aigner, R., Bogdahn, U., Winkler, J., Hoehn, M., Aigner, L., 2008. In vivo optical imaging of neurogenesis: watching new neurons in the intact brain. Mol. Imaging 7, 28-34. http://dx.doi.org/ 10.2310/7290.2008.0004.

Curtis, M.A., Penney, E.B., Pearson, J., Dragunow, M., Connor, B., Faull, R.L.M., 2005. The distribution of progenitor cells in the subependymal layer of the lateral ventricle in the normal and Huntington's disease human brain. Neuroscience 132, 777-788. http://dx.doi.org/10.1016/j.neuroscience.2004.12.051.

DeCarolis, N.A., Mechanic, M., Petrik, D., Carlton, A., Ables, J.L., Malhotra, S., Bachoo, R. Götz, M., Lagace, D.C., Eisch, A.J., 2013. In vivo contribution of nestin- and GLAST-lineage cells to adult hippocampal neurogenesis. Hippocampus 23, 708-719. http://dx.doi.org/10.1002/hipo.22130.

Deierborg, T., Staflin, K., Pesic, J., Roybon, L., Brundin, P., Lundberg, C., 2009. Absence of striatal newborn neurons with mature phenotype following defined striatal and cortical excitotoxic brain injuries. Exp. Neurol. 219, 363-367. http://dx.doi.org/10.1016/j. expneurol.2009.05.002

Deroose, C.M., Reumers, V., Gijsbers, R., Bormans, G., Debyser, Z., Mortelmans, L., Baekelandt, V., 2006. Noninvasive monitoring of long-term lentiviral vectormediated gene expression in rodent brain with bioluminescence imaging. Mol. Ther. 14, 423-431. http://dx.doi.org/10.1016/j.ymthe.2006.05.007.

Dhaliwal, J., Lagace, D.C., 2011. Visualization and genetic manipulation of adult neurogenesis using transgenic mice. Eur. J. Neurosci. 33, 1025-1036. http://dx.doi. org/10.1111/j.1460-9568.2011.07600.x

Dirnagl, U., members of the MCAO-SOP group, 2009. Standard operating procedures (SOP) in experimental stroke research: SOP for middle cerebral artery occlusion in the mouse. Nature Precedings. http://dx.doi.org/10.1038/npre.2009.3492.1.

Eriksson, P.S., Perfilieva, E., Björk-Eriksson, T. Alborn, A.M., Nordborg C., Peterson, D.A., Gage, F.H., 1998. Neurogenesis in the adult human hippocampus. Nat. Med. 4, 1313-1317. http://dx.doi.org/10.1038/3305.

Flynn, R.W.V., MacWalter, R.S.M., Doney, A.S.F., 2008. The cost of cerebral ischaemia Neuropharmacology 55, 250-256. http://dx.doi.org/10.1016/j.neuropharm.2008.05. 031.

Geraerts, M., Michiels, M., Baekelandt, V., Debyser, Z., Gijsbers, R., 2005. Upscaling of lentiviral vector production by tangential flow filtration. J. Gene Med. 7, 1299-1310. http://dx.doi.org/10.1002/jgm.778.
Geraerts, M., Eggermont, K., Hernandez-Acosta, P., Garcia-Verdugo, J.-M., Baekelandt, V. Debyser, Z., 2006. Lentiviral vectors mediate efficient and stable gene transfer in adult neural stem cells in vivo. Hum. Gene Ther. 17, 635-650. http://dx.doi.org/10. 1089/hum.2006.17.635

Giachino, C., Basak, O., Lugert, S., Knuckles, P., Obernier, K., Fiorelli, R., Frank, S., Raineteau, O., Alvarez-Buylla, A., Taylor, V., 2013. Molecular diversity subdivides the adult forebrain neural stem cell population. Stem Cells. http://dx.doi.org/10.1002/stem.1520.

Goings, G.E., Sahni, V., Szele, F.G., 2004. Migration patterns of subventricular zone cells in adult mice change after cerebral cortex injury. Brain Res. 996, 213-226. http://dx.doi. org/10.1002/jnr.22109.

Gray, W.P., Sundstrom, L.E., 1998. Kainic acid increases the proliferation of granule cell progenitors in the dentate gyrus of the adult rat. Brain Res. 790, 52-59. http://dx. doi.org/10.1016/S0006-8993(98)00030-4.

Guglielmetti, C., Praet, J., Rangarajan, J.R., Vreys, R., De Vocht, N., Maes, F., Verhoye, M., Ponsaerts, P., Van der Linden, A., 2013. Multimodal imaging of subventricular zone neural stem/progenitor cells in the cuprizone mouse model reveals increased neurogenic potential for the olfactory bulb pathway, but no contribution to remyelination of the corpus callosum. Neurolmage. http://dx.doi.org/10.1016/j.neuroimage.2013. 07.080 (Epub ahead of print)

Holmin, S., Almqvist, P., Lendahl, U., Mathiesen, T., 1997. Adult nestin-expressing subependymal cells differentiate to astrocytes in response to brain injury. Eur. J. Neurosci. 9, 65-75.

Ibrahimi, A., Vande Velde, G., Reumers, V., Toelen, J., Thiry, I., Vandeputte, C., Vets, S. Deroose, C., Bormans, G., Baekelandt, V., Debyser, Z., Gijsbers, R., 2009. Highly efficient multicistronic lentiviral vectors with peptide $2 \mathrm{~A}$ sequences. Hum. Gene Ther. 20, 845-860. http://dx.doi.org/10.1089/hum.2008.188.

Jin, K., Minami, M., Lan, J.Q., Mao, X.O., Batteur, S., Simon, R.P., Greenberg, D.A., 2001. Neurogenesis in dentate subgranular zone and rostral subventricular zone after focal cerebral ischemia in the rat. Proc. Natl. Acad. Sci. U. S. A. 98, 4710-4715. http://dx.doi.org/10.1073/pnas.081011098.

Karki, K., Knight, R.A., Shen, L.H., Kapke, A., Lu, M., Li, Y., Chopp, M., 2010. Chronic brain tissue remodeling after stroke in rat: a 1-year multiparametric magnetic resonance imaging study. Brain Res. 1360, 168-176. http://dx.doi.org/10.1016/j.brainres.2010. 08.098.

Kempermann, G., Kuhn, H.G., Gage, F.H., 1997. Genetic influence on neurogenesis in the dentate gyrus of adult mice. Proc. Natl. Acad. Sci. U. S. A. 94, 10409-10414.

Kernie, S.G., Parent, J.M., 2010. Forebrain neurogenesis after focal Ischemic and traumatic brain injury. Neurobiol. Dis. 37, 267-274. http://dx.doi.org/10.1016/j.nbd.2009.11. 002.

Komitova, M., Perfilieva, E., Mattsson, B., Eriksson, P.S., Johansson, B.B., 2006. Enriched environment after focal cortical ischemia enhances the generation of astroglia and NG2 positive polydendrocytes in adult rat neocortex. Exp. Neurol. 199, 113-121. http://dx doi.org/10.1016/j.expneurol.2005.12.007.

Lagace, D.C., Whitman, M.C., Noonan, M.A., Ables, J.L., DeCarolis, N.A., Arguello, A.A. Donovan, M.H., Fischer, S.J., Farnbauch, L.A., Beech, R.D., DiLeone, R.J., Greer, C.A. Mandyam, C.D., Eisch, A.J., 2007. Dynamic contribution of nestin-expressing stem cells to adult neurogenesis. J. Neurosci. 27, 12623-12629. http://dx.doi.org/10.1523/ JNEUROSCI.3812-07.2007.

Lemberger, T., Parlato, R., Dassesse, D., Westphal, M., Casanova, E., Turiault, M., Tronche, F. Schiffmann, S.N., Schütz, G., 2007. Expression of Cre recombinase in dopaminoceptive neurons. BMC Neurosci. 8, 4. http://dx.doi.org/10.1186/1471-2202-8-4.

Li, Y., Chopp, M., 1999. Temporal profile of nestin expression after focal cerebral ischemia in adult rat. Brain Res. 838, 1-10. http://dx.doi.org/10.1016/S0006-8993(99)01502-4.

Li, L., Harms, K.M., Ventura, P.B., Lagace, D.C., Eisch, A.J., Cunningham, L.A., 2010. Focal cerebral ischemia induces a multilineage cytogenic response from adult subventricular zone that is predominantly gliogenic. Glia 58, 1610-1619. http://dx.doi.org/10.1002/ glia.21033.

Liu, J., Solway, K., Messing, R.O., Sharp, F.R., 1998. Increased neurogenesis in the dentate gyrus after transient global ischemia in gerbils. J. Neurosci. 18, 7768-7778.

Liu, F., You, Y., Li, X., Ma, T., Nie, Y., Wei, B., Li, T., Lin, H., Yang, Z., 2009. Brain injury does not alter the intrinsic differentiation potential of adult neuroblasts. J. Neurosci. 29, 5075-5087. http://dx.doi.org/10.1523/JNEUROSCI.0201-09.2009.

Massoud, T.F., Gambhir, S.S., 2003. Molecular imaging in living subjects: seeing fundamental biological processes in a new light. Genes Dev. 17, 545-580. http://dx.doi org/10.1101/gad.1047403.

Ming, G., Song, H., 2005. Adult neurogenesis in the mammalian central nervous system. Annu. Rev. Neurosci. 28, 223-250. http://dx.doi.org/10.1146/annurev.neuro.28. 051804.101459.

Nieman, B.J., Shyu, J.Y., Rodriguez, J.J., Garcia, A.D., Joyner, A.L., Turnbull, D.H., 2010. In vivo MRI of neural cell migration dynamics in the mouse brain. Neurolmage 50, 456-464 http://dx.doi.org/10.1016/j.neuroimage.2009.12.107.

Ohab, J.J., Carmichael, S.T., 2008. Poststroke neurogenesis: emerging principles of migration and localization of immature neurons. Neuroscientist 14, 369-380. http://dx doi.org/10.1177/1073858407309545.

Ohab, J.J., Fleming, S., Blesch, A., Carmichael, S.T., 2006. A neurovascular niche for neurogenesis after stroke. J. Neurosci. 26, 13007-13016. http://dx.doi.org/10.1523/ JNEUROSCI.4323-06.2006.

Oosterlinck, W.W., Dresselaers, T., Geldhof, V., Van Santvoort, A., Robberecht, W. Herijgers, P., Himmelreich, U., 2011. Response of mouse brain perfusion to hypoand hyperventilation measured by arterial spin labeling. Magn. Reson. Med. 66 802-811. http://dx.doi.org/10.1002/mrm.23060.

Parent, J.M., Vexler, Z.S., Gong, C., Derugin, N., Ferriero, D.M., 2002. Rat forebrain neurogenesis and striatal neuron replacement after focal stroke. Ann. Neurol. 52 802-813. http://dx.doi.org/10.1002/ana.10393.

Reumers, V., Deroose, C.M., Krylyshkina, O., Nuyts, J., Geraerts, M., Mortelmans, L., Gijsbers, R., Van den Haute, C., Debyser, Z., Baekelandt, V., 2008. Noninvasive and 
quantitative monitoring of adult neuronal stem cell migration in mouse brain using bioluminescence imaging. Stem Cells 26, 2382-2390. http://dx.doi.org/10.1634/ stemcells.2007-1062.

Rueger, M.A., Backes, H., Walberer, M., Neumaier, B., Ullrich, R., Simard, M.-L., Emig, B. Fink, G.R., Hoehn, M., Graf, R., Schroeter, M., 2010. Noninvasive imaging of endogenous neural stem cell mobilization in vivo using positron emission tomography. J. Neurosci. 30, 6454-6460. http://dx.doi.org/10.1523/JNEUROSCI.6092-09.2010.

Safran, M., Kim, W.Y., Kung, A.L., Horner, J.W., DePinho, R.A., Kaelin Jr., W.G., 2003. Mouse reporter strain for noninvasive bioluminescent imaging of cells that have undergone Cre-mediated recombination. Mol. Imaging 2, 297-302.

Shapiro, E.M., Gonzalez-Perez, O., Manuel García-Verdugo, J., Alvarez-Buylla, A., Koretsky, A.P., 2006. Magnetic resonance imaging of the migration of neuronal precursors generated in the adult rodent brain. Neuroimage 32, 1150-1157. http://dx.doi.org/10. 1016/j.neuroimage.2006.04.219.

Shimada, I.S., Peterson, B.M., Spees, J.L., 2010. Isolation of locally derived stem/progenitor cells from the peri-infarct area that do not migrate from the lateral ventricle after cortical stroke. Stroke 41, e552-e560. http://dx.doi.org/10.1161/STROKEAHA.110. 589010.

Shin, Y.-J., Kim, H.L., Park, J.-M., Cho, J.M., Kim, S.Y., Lee, M.-Y., 2013. Characterization of nestin expression and vessel association in the ischemic core following focal cerebral ischemia in rats. Cell Tissue Res. 351, 383-395. http://dx.doi.org/10.1007/s00441012-1538-X.

Sirko, S., Behrendt, G., Johansson, P.A., Tripathi, P., Costa, M.R., Bek, S., Heinrich, C., Tiedt, S., Colak, D., Dichgans, M., Fischer, I.R., Plesnila, N., Staufenbiel, M., Haass, C., Snapyan, M., Saghatelyan, A., Tsai, L.-H., Fischer, A., Grobe, K., Dimou, L., Götz, M., 2013. Reactive glia in the injured brain acquire stem cell properties in response to sonic hedgehog. Cell Stem Cell 12, 426-439. http://dx.doi.org/10.1016/j.stem.2013.01.019.

Sumner, J.P., Shapiro, E.M., Maric, D., Conroy, R., Koretsky, A.P., 2009. In vivo labeling of adult neural progenitors for MRI with micron sized particles of iron oxide: quantifica- tion of labeled cell phenotype. Neuroimage 44, 671-678. http://dx.doi.org/10.1016/j. neuroimage.2008.07.050.

Thored, P., Wood, J., Arvidsson, A., Cammenga, J., Kokaia, Z., Lindvall, O., 2007. Long-term neuroblast migration along blood vessels in an area with transient angiogenesis and increased vascularization after stroke. Stroke 38, 3032-3039. http://dx.doi.org/10. 1161/STROKEAHA.107.488445.

Tronche, F., Kellendonk, C., Kretz, O., Gass, P., Anlag, K., Orban, P.C., Bock, R., Klein, R., Schütz, G., 1999. Disruption of the glucocorticoid receptor gene in the nervous system results in reduced anxiety. Nat. Genet. 23, 99-103. http://dx.doi.org/10.1038/12703.

Vande Velde, G., Raman Rangarajan, J., Vreys, R., Guglielmetti, C., Dresselaers, T., Verhoye, M., Van der Linden, A., Debyser, Z., Baekelandt, V., Maes, F., Himmelreich, U., 2012. Quantitative evaluation of MRI-based tracking of ferritin-labeled endogenous neural stem cell progeny in rodent brain. NeuroImage 62, 367-380. http://dx.doi.org/10. 1016/j.neuroimage.2012.04.040.

Vandeputte, C., Thomas, D. Dresselaers, T., Crabbe, A, Verfaillie, C., Baekelandt, V., Van Laere, K., Himmelreich, U., 2011. Characterization of the inflammatory response in a photothrombotic stroke model by MRI: implications for stem cell transplantation. Mol. Imaging Biol. 13, 663-671. http://dx.doi.org/10.1007/s11307-010-0395-9.

Vreys, R., Vande Velde, G., Krylychkina, O., Vellema, M., Verhoye, M., Timmermans, J.-P., Baekelandt, V., Van der Linden, A., 2010. MRI visualization of endogenous neural progenitor cell migration along the RMS in the adult mouse brain: validation of various MPIO labeling strategies. Neuroimage 49, 2094-2103. http://dx.doi.org/10.1016/j. neuroimage.2009.10.034.

Watson, B.D., Dietrich, W.D., Busto, R., Wachtel, M.S., Ginsberg, M.D., 1985. Induction of reproducible brain infarction by photochemically initiated thrombosis. Ann. Neurol. 17, 497-504. http://dx.doi.org/10.1002/ana.410170513.

Zhang, R.L., Zhang, Z.G., Chopp, M., 2008. Ischemic stroke and neurogenesis in the subventricular zone. Neuropharmacology 55, 345-352. http://dx.doi.org/10.1016/j. neuropharm.2008.05.027. 